\title{
Molecular Structure, Infrared Spectrum, and Photochemistry of Squaric Acid Dimethyl Ester in Solid Argon
}

\author{
S. Breda, ${ }^{\dagger,+}$ I. Reva, ${ }^{\dagger}$ L. Lapinski, ${ }^{\dagger,+}$ and R. Fausto ${ }^{*, \dagger}$ \\ Department of Chemistry, University of Coimbra, P-3004-535 Coimbra, Portugal, and Institute of Physics, \\ Polish Academy of Sciences, Warsaw, PL-02-668, Poland
}

Received: May 26, 2006; In Final Form: July 26, 2006

\begin{abstract}
Squaric acid dimethyl ester $\left(\mathrm{C}_{6} \mathrm{O}_{4} \mathrm{H}_{6} ; 3\right.$,4-dimethoxycyclobut-3-ene-1,2-dione; DCD) was studied by matrix isolation infrared spectroscopy and by density functional theory (B3LYP) and ab initio (MP2) calculations with the $6-31++\mathrm{G}(\mathrm{d}, \mathrm{p})$ and $6-311++\mathrm{G}(\mathrm{d}, \mathrm{p})$ basis sets. Three conformers of the compound were theoretically predicted. The two most stable conformers were identified in low-temperature argon matrixes and the energy gap between them was determined. The trans-trans conformer $\left(C_{2 v}\right)$ was found to be more stable than the cis - trans form $\left(\mathrm{C}_{\mathrm{s}}\right)$ by $4.2 \mathrm{~kJ} \mathrm{~mol}^{-1}$, in consonance with the theoretical predictions $(\mathrm{MP} 2 \mathrm{calcd}=3.9 \mathrm{~kJ}$ $\left.\mathrm{mol}^{-1}\right)$. In situ broadband UV irradiation $(\lambda>337 \mathrm{~nm})$ of the matrix-isolated compound was found to induce the ring-opening reaction leading to production of the bisketene, 2,3-dimethoxybuta-1,3-diene-1,4-dione as well as the trans - trans $\rightarrow$ cis - trans conformational isomerization. The latter phototransformation allowed separation of the infrared spectra of the two conformers initially trapped into a low-temperature matrix. Upon higher energy irradiation $(\lambda>235 \mathrm{~nm})$, the main observed photoproducts were $\mathrm{CO}$ and deltic acid dimethyl ester $\left(\mathrm{C}_{5} \mathrm{O}_{3} \mathrm{H}_{6} ; 2\right.$,3-dimethoxycycloprop-2-en-1-one), the latter being obtained in two different conformations (trans - trans and cis-trans). According to the experimental data, deltic acid dimethyl ester is produced by decarbonylation of the initially formed bisketene and not by direct CO extrusion from DCD.
\end{abstract}

\section{Introduction}

The derivatives of cyclobut-3-ene-1,2-dione have applications in many domains, from medicine and pharmacology (for example, as antiulcer agents and analgesics ${ }^{1-3}$ ) to photography and energy storing devices. ${ }^{4,5}$

Squaric acid $\left(\mathrm{C}_{4} \mathrm{O}_{4} \mathrm{H}_{2} ; 3\right.$,4-dihydroxyclobut-3-ene-1,2-dione) is one of the simplest derivatives of cyclobut-3-ene-1,2-dione. This compound presents very interesting physicochemical properties, including unusually strong acidity (comparable to that of sulfuric acid) as well as a considerable degree of aromaticity. ${ }^{6}$ Some of the derivatives of squaric acid, such as diesters, diamides and mixed amide-esters, were reported to have relatively high nonlinear optical activity, being major potential materials for second harmonic generators of laser light. ${ }^{7,8}$

Despite their potential applications, these types of compounds have been scarcely studied. In the monomeric form, even squaric acid itself has not been much studied. In 1997, Rostkowska et al. ${ }^{9}$ reported the infrared spectra of the compound isolated in low-temperature $\mathrm{Ar}$ and $\mathrm{N}_{2}$ matrixes. The two most stable conformers of squaric acid, predicted theoretically [at the DFT/ B3LYP/6-31++G(d,p) level], were considered as possible structures of the matrix-isolated monomers. Though the authors favored the prevalence of the trans - trans conformer $\left(C_{2 v}\right.$; with both $\mathrm{OH}$ groups in trans orientation with respect to the $\mathrm{C}=\mathrm{C}$ bond) in the matrixes, the spectroscopic differentiation between the two conformers could not be unequivocally made, since their predicted infrared spectra were found to be nearly coincident in all but the $\mathrm{OH}$ stretching region. In addition, the spectral profile in this latter spectral range was found to be strongly

* To whom correspondence should be addressed. E-mail: rfausto@ci.uc.pt.

$\doteqdot$ University of Coimbra.

$\doteqdot$ Polish Academy of Sciences. dependent on the matrix gas, with the number of observed bands varying from argon to nitrogen matrix. ${ }^{9}$ On the other hand, in the crystalline state, molecules of squaric acid are well-known to exist in the cis-trans conformation. ${ }^{10-13}$

Squaric acid dimethyl ester $\left(\mathrm{C}_{6} \mathrm{O}_{4} \mathrm{H}_{6} ; 3\right.$,4-dimethoxycyclobut3-ene-1,2-dione; from here abbreviated as DCD) differs from its parent compound by substitution of the two acid hydrogen atoms by methyl groups. In the nonmethylated compound both conformers are stabilized by intramolecular hydrogen bonds. The $C_{2 v}$ conformer involves two equal $\mathrm{O}-\mathrm{H} \cdots \mathrm{O}=\mathrm{C}$ bonds, whereas in the $C_{s}$ form the intramolecular hydrogen bonds are different and belong to the $\mathrm{O}-\mathrm{H} \cdots \mathrm{O}=\mathrm{C}$ and $\mathrm{O}-\mathrm{H} \cdots \mathrm{O}-\mathrm{C}$ types. Most likely, this difference in the intramolecular hydrogen bonding results in a destabilization of the $\mathrm{C}_{\mathrm{s}}$ conformer with respect to the $C_{2 v}$ form by $8 \mathrm{~kJ} \mathrm{~mol}^{-1}$ (according to the MP2 calculations, ${ }^{9}$ ). In the methylated compound the two most stable conformers have geometries similar to those of squaric acid, but the possibility of intramolecular hydrogen bond formation is absent in both forms. From this point of view, one can expect that the destabilization of the minor conformer in the methylated compound would be less pronounced, or in other words, that the two conformers would be separated by a smaller energy gap. That is why, it can be expected that the two most stable conformers predicted theoretically for DCD would be also important experimentally. In addition, their spectroscopic differentiation can be anticipated to be easier, because the presence of a methyl groups implies an increased number of observable bands and can also be expected to give rise to more pronounced vibrational coupling in the molecule, which in turn shall lead to an enhanced dependence of the vibrational spectra on the conformation. Thus, the spectroscopic study of DCD appears to be an interesting possibility to undertake the first detailed 
SCHEME 1: Conformers and Atom Numbering for Squaric Acid Dimethyl Ester. ${ }^{a}$

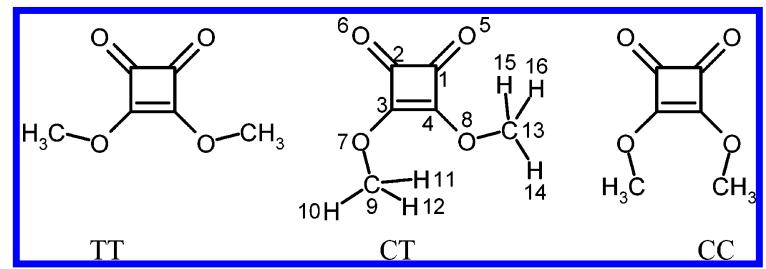

${ }^{a}$ Conformers are named by the values of two $\mathrm{C}=\mathrm{C}-\mathrm{O}-\mathrm{C}$ dihedral angles: $\mathrm{T}=$ trans, $\mathrm{C}=$ cis.

experimental conformational and vibrational characterization of a molecule based on the squaric acid framework.

Another interesting question that was still open to further investigation is the photochemical reactivity of squaric acid derivatives. Already in 1961, the photochemical ring opening of cyclobutene-1,2-diones was reported simultaneously by Mallory and Roberts ${ }^{14}$ and Blomquist and LaLancette. ${ }^{15}$ Since that time, this reaction has been used to generate 1,2-bisketenes, but usually these species have only been observed at low temperature, often in matrixes, because of their facile thermal ring closure. ${ }^{16-23}$ Observation of deltic acid $\left(\mathrm{C}_{3} \mathrm{O}_{3} \mathrm{H}_{2} ; 2,3\right.$ dihydroxycycloprop-2-en-1-one) as a photoproduct generated from squaric acid was also reported. ${ }^{22,23}$ Maier and Rohr ${ }^{22}$ noticed that the deltic acid, produced by irradiation of the matrixisolated squaric acid, gives rise to at least two bands owing to $\mathrm{OH}$ stretching vibrations $(\nu \mathrm{OH})$, whereas the trans - trans conformer of this compound should give rise to only one infrared-active $\nu \mathrm{OH}$ band. Nevertheless, the experimental results were interpreted assuming the presence of only the trans - trans conformer. The experimentally observed additional band was interpreted as a result of the interaction of one of the $\mathrm{OH}$ groups with the $\mathrm{CO}$ molecule produced in the same matrix cage. However, the presence of a second conformer in the photolyzed matrix cannot be ruled out on the basis of the experimental data. By the same reasons as those mentioned above (regarding the advantage of studying the dimethyl ester of squaric acid instead of the acid itself in order to attain an unequivocal spectroscopic identification of its possible conformers), the study of the dimethyl ester of deltic acid (if it could be produced from photolysis of DCD) would also be of interest to the conformational and vibrational characterization of the deltic acid framework.

Taking into consideration all the points addressed above, we have studied DCD (and its photoproducts) by a combined matrix isolation infrared spectroscopy and theoretical [DFT/B3LYP and MP2] approach. As it will be described in detail in the next sections, both trans-trans and cis-trans conformers of DCD were found to be present in the as-deposited matrixes, the transtrans conformer corresponding to the most stable form. UVirradiation of the compound was found to lead to trans - trans $\rightarrow$ cis - trans conformational isomerization as well as to ringopening photoreaction generating isomeric forms of the bisketene. Upon subsequent photolysis, the latter compound yielded the dimethyl ester of deltic acid $\left(\mathrm{C}_{5} \mathrm{O}_{3} \mathrm{H}_{6} ; 2,3\right.$-dimethoxycycloprop-2-en-1-one; DCP) in both trans - trans and cis - trans stable conformations. Unequivocal experimental identification and vibrational characterization of the two conformers of both DCD and DCP was achieved, constituting the first successful attempt to do so for molecules with the squaric or deltic acids' frameworks.

\section{Experimental and Computational Details}

A sample of the DCD (Aldrich, 99\%) was placed in a glass tube protected against light and connected to the chamber of

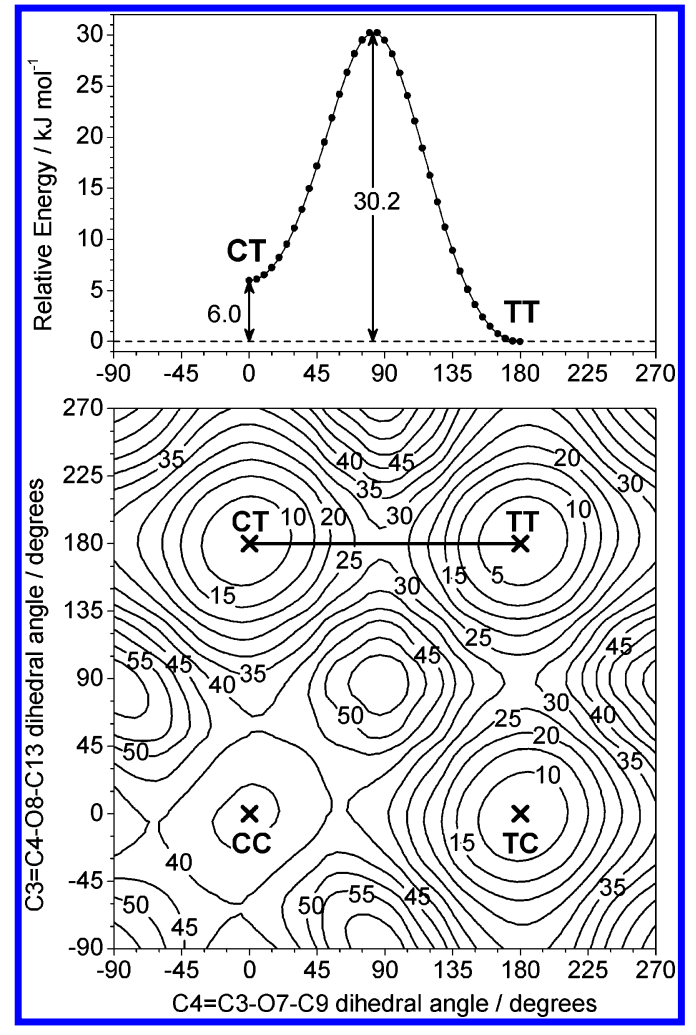

Figure 1. Potential energy map showing the dependence of energy on internal rotation of the two methoxyl groups in DCD (bottom) and potential energy profile for interconversion between conformers CT and TT (top). Calculations at the DFT(B3LYP)/6-311++G(d,p) level of theory. The potential energy map was built by varying the $\mathrm{C} 3=$ $\mathrm{C} 4-\mathrm{O} 8-\mathrm{C} 13$ and $\mathrm{C} 4=\mathrm{C} 3-\mathrm{O} 7-\mathrm{C} 9$ dihedral angles in steps of $5 \mathrm{deg}$ and letting all the remaining internal coordinates adjust to their optimal values. Minima are indicated in the graph by crosses $(x)$ and labeled by conformer names (CC, CT, TC, TT). Forms TC and CT are degenerated. Energies are relative to the most stable conformer (TT) and do not include zero-point vibrational corrections. Isoenergy levels are spaced by $5 \mathrm{~kJ} \mathrm{~mol}^{-1}$.

the cryostat with a needle valve. To deposit a matrix, the vapor of DCD was introduced into the cryostat chamber through the needle valve together with large excess of the host matrix gas (argon N60 from Air Liquide) coming from a separate line. The needle valve has two thermostatable parts: the valve nozzle and the sample compartment. The sample compartment during deposition was kept in all experiments at room temperature (23 ${ }^{\circ} \mathrm{C}$ ), which was sufficient to sublimate the compound (mp 55$57^{\circ} \mathrm{C}$ ) and provide enough vapor pressure. The temperature of the valve nozzle in different experiments was varied between 23 and $158{ }^{\circ} \mathrm{C}$. This allowed control of the equilibrium conformational populations in the gaseous phase prior to the deposition of matrixes and helped in experimental estimation of the enthalpy difference between the two main forms. A cold CsI window mounted on the tip of an APD Cryogenics DE202A closed-cycle helium refrigerator was used as the optical substrate and kept during the deposition of all samples at the lowest possible temperature, $10 \mathrm{~K}$.

The matrixes were irradiated with filtered (using long-pass filters $375,337,285 \mathrm{~nm}$ ) or unfiltered light from a $150 \mathrm{~W}$ xenon arc lamp (Osram XBO 150W/CR OFR) through the outer $\mathrm{KBr}$ window of the cryostat. The infrared spectra were recorded with $0.5 \mathrm{~cm}^{-1}$ resolution using a Mattson (60AR) Infinity Series FTIR spectrometer equipped with a $\mathrm{KBr}$ beam splitter and a DTGS detector. The UV absorption spectrum of the compound as a solid-state thin film was recorded on a Shimadzu UV-2100 spectrometer. The thin film was obtained by deposition of a 
few drops from a solution of the compounds into a circular sapphire substrate (10 mm diameter) followed by spin coating (using a Desk-Top precision spin coating system, model P6700 series from Speedline Technologies; $2500 \mathrm{rpm}$ ) in a nitrogen saturated atmosphere ( $2 \mathrm{psi}$ ). The solutions for spin-coating were prepared by adding $2 \mathrm{mg}$ of the samples to $15 \mathrm{mg}$ of Zeonex in $200 \mu \mathrm{L}$ of toluene solution with stirring at $40{ }^{\circ} \mathrm{C}$ for $30 \mathrm{~min}$.

The equilibrium geometries for all studied species were fully optimized at the DFT(B3LYP) $)^{24,25}$ and MP2 levels ${ }^{26}$ of theory with the standard 6-311++G(d,p) and 6-31++G(d,p) basis sets, respectively, using explicit symmetries whenever possible. Both methods, MP2 and DFT, account for significant parts of electron correlation energy. Hence, these methods should provide values of relative energy of CT and TT conformers being in fair agreement with experiment. However, because one of the methods accounts only for dynamic part of the electron correlation and the other is not able to account for the dispersive part of the electron correlation, theoretical predictions close to exact could be obtained (using MP2 or DFT approaches) only in the case of fortunate cancellation of errors. Nevertheless, the practice demonstrated that, as far as calculations of relative conformational energies are concerned, the performance of the MP2 method is slightly better, whereas the DFT method usually yields somewhat better vibrational frequencies. Then, since the MP2 is considerably more expensive in terms of computational resources, it was used in the present study only to estimate the energy differences between the experimentally relevant conformers of DCD. The nature of the obtained stationary points on the potential energy surfaces of the respective systems was checked through the analysis of the corresponding Hessian matrix. For the cases where imaginary frequencies were present, optimizations of geometry and calculations of vibrational frequencies were repeated with reduced symmetries, until no imaginary frequencies were obtained. For minimum energy structures, a set of internal coordinates was defined, and the Cartesian force constants were transformed to the internal coordinates space, allowing ordinary normal-coordinate analysis to be performed as described by Schachtschneider. ${ }^{27}$ The theoretically predicted spectra were used to assist the analysis of the experimental spectra. The calculated harmonic frequencies were scaled according to the equation $v_{\text {(scaled) }}=26.8+$

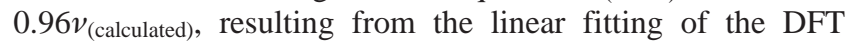
calculated frequencies to the experimentally observed frequencies. Internal coordinate sets defined for DCD and all identified photoproducts are given in Tables S01-S07 (Supporting Information). Atom numbering schemes for the studied structures are given in Scheme 1 and Figures S02-S04 (Supporting Information).

All calculations in this work were done using the Windows version of the Gaussian 98 program. ${ }^{28}$

\section{Results and Discussion}

Geometries and Energies. The molecule of DCD has two intramolecular torsional degrees of freedom that correspond to rotations of the $-\left(\mathrm{O}-\mathrm{CH}_{3}\right)$ groups with respect to the fourmembered ring and can result in different conformations. A detailed conformational analysis of the potential energy surface (PES) of DCD was carried out theoretically at the DFT(B3LYP)/ 6-311++G(d,p) level by calculating a two-dimensional grid of points as a function of the $\mathrm{C} 3=\mathrm{C} 4-\mathrm{O} 8-\mathrm{C} 13$ and $\mathrm{C} 4=\mathrm{C} 3-$ O7-C9 dihedral angles. These angles were incrementally changed in steps of $5 \mathrm{deg}$ and all remaining internal coordinates were optimized (Figure 1). Three different minima were obtained (Scheme 1), one of them corresponding to a doubly
TABLE 1: DFT and MP2/6-311 $++G(d, p)$ Calculated Relative Energies $\left(\Delta E^{\circ} / \mathrm{kJ} \mathrm{mol}^{-1}\right)$, Zero-Point Vibrational Energy Corrected Relative Energies $\left(\Delta E^{\circ}{ }_{\mathrm{ZPVE}} / \mathrm{kJ} \mathrm{mol}^{-1}\right)$ and Dipole Moments $(|\boldsymbol{\mu}| /$ debye $)$ for Relevant Structures of $\mathrm{DCD}^{a}$

\begin{tabular}{|c|c|c|c|c|}
\hline & & MP2 & DFT(B3LYP) & \\
\hline Structure & Symmetry & $\overline{\Delta \mathrm{E}^{\circ}}$ & $\Delta \mathrm{E}_{\mathrm{ZPVB}}^{\mathrm{o}}$ & $|\mu|$ \\
\hline
\end{tabular}

\section{CONFORMER I}

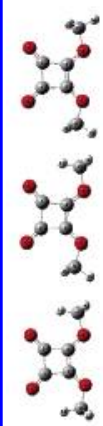

$\mathrm{C}_{2 \mathrm{v}}$

$-$

$-$

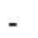

4.57

$\mathrm{C}_{\mathrm{s}}$

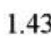

1.86

$\mathrm{C}_{2 \mathrm{v}}$

2.90

3.06

\section{CONFORMER II}

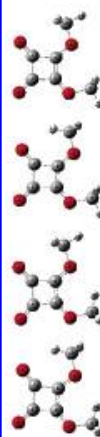

$\mathrm{C}_{\mathrm{s}}$

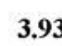

6.54

7.26

$\mathrm{C}_{\mathrm{s}}$

1.88

1.69

$\mathrm{C}_{s}$

3.30

2.94

$\mathrm{C}_{\mathrm{s}}$

5.12

4.62

\section{CONFORMER III}

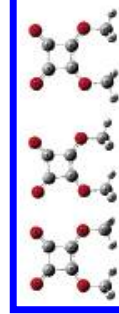
$\mathrm{C}_{2 \mathrm{v}}$
$\mathrm{C}_{\mathrm{s}}$ 34.7

34.98

36.29

9.06

11.30

10.10

25.98

${ }^{a}$ For the minimum energy structures tabulated, values are given in bold. DFT values of $E^{\circ}$ and $E_{\text {ZPVE }}^{\circ}$ for the most stable conformer (form I) are -533.22598763 and -533.111408 hartree $(1$ hartree $=2625.5001$ $\mathrm{kJ} \mathrm{mol}^{-1}$ ), respectively. MP2 calculated $E^{\circ}$ for conformer $\mathrm{I}$ is -531.828892208 hartree. For structures that do not correspond to a minimum on the potential energy surface, $\Delta E^{\circ}$ and $\Delta E^{\circ}{ }_{\mathrm{ZPVE}}$ are calculated in relation to the parent minimum with the same heavy atom backbone.

degenerated-by-symmetry form. From here onward, the conformers will be named with respect to the values of two dihedral $\mathrm{C}=\mathrm{C}-\mathrm{O}-\mathrm{C}$ angles using notation " $\mathrm{T}$ " (trans, $180^{\circ}$ ) and " $\mathrm{C}$ " (cis, $0^{\circ}$ ). The three possible combinations are TT, CT (equal to TC), and CC. Similarly as it was previously found for squaric acid, ${ }^{9}$ the most stable form predicted by the calculations is the trans-trans conformer of $C_{2 v}$ symmetry (form TT in Figure 1 and Scheme 1). The second most stable form was found to be the doubly degenerated-by-symmetry cis - trans, $C_{s}$ symmetry form (CT), with the DFT calculated energy higher by ca. $6 \mathrm{~kJ}$ $\mathrm{mol}^{-1}$ with respect to the most stable TT conformer. The energy 


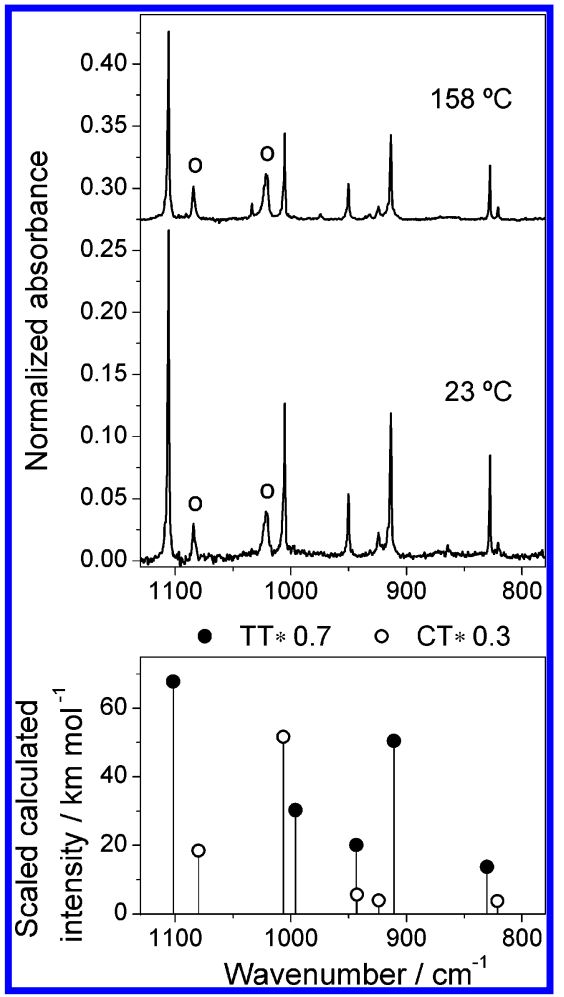

Figure 2. Shown in the upper frame is a fragment of the infrared spectra of DCD isolated in argon matrixes at $10 \mathrm{~K}$. The matrixes were deposited from vapor of the compound at $158{ }^{\circ} \mathrm{C}$ and at $23{ }^{\circ} \mathrm{C}$. Experimental spectra were normalized so that the bands due to conformer CT (marked by circles) are equally intense in both of them. The spectra are shifted on ordinate for clarity. The lower frame shows the corresponding fragment of the infrared spectra calculated at the DFT(B3LYP)/6-311++G(d,p) level for DCD conformers TT (full circles) and CT (open circles). Intensities in the calculated spectra were multiplied by the estimated relative populations of the two conformers at $23{ }^{\circ} \mathrm{C}(70 \%$ and $30 \%)$, taking into account the experimentally estimated difference in enthalpies of the conformers. All theoretical frequencies are scaled using the equation $v_{\text {scaled }}=26.8+0.96 v_{\text {calcd }}$. Note that in the spectra obtained from the vapor of the compound at $158{ }^{\circ} \mathrm{C}$ some very-low-intensity bands (e.g., at 1034 and $974 \mathrm{~cm}^{-1}$ ) resulting from thermal decomposition of DCD are observed. However, at this temperature, the amount of DCD undergoing thermal decomposition is still negligible. The study of the pyrolitic decomposition of DCD is not addressed in this work.

difference between CT and TT calculated at the MP2/6$311++\mathrm{G}(\mathrm{d}, \mathrm{p})$ level is equal to $3.9 \mathrm{~kJ} \mathrm{~mol}^{-1}$. The height of the barrier separating CT from the most stable conformer TT was predicted by the DFT calculations to be equal to $24.2 \mathrm{~kJ} \mathrm{~mol}^{-1}$ (see Figure 1). A minimum corresponding to the third conformer, cis-cis $\left(C_{2 v}\right.$ symmetry; CC), was also found on the PES of DCD. The DFT calculated energy of this form is higher than that of the TT conformer by as much as $35 \mathrm{~kJ} \mathrm{~mol}^{-1}$. Thus the $\mathrm{CC}$ form should be of no practical relevance.

In all three conformers, the methyl groups adopt a configuration where one of the hydrogen atoms is anti-periplanar relative to the ring carbon atom to which the corresponding methoxyl group is bound (see Table 1). For a trans-methoxyl group, the barrier to methyl internal rotation was predicted by DFT method to be less than $2 \mathrm{~kJ} \mathrm{~mol}^{-1}$, while for a cis-methoxyl group the barrier was found to be considerably larger: in CT, it amounts to ca. $3 \mathrm{~kJ} \mathrm{~mol}^{-1}$, and in $\mathrm{CC}$, where the methyl groups are in close contact to each other, it is larger than $10 \mathrm{~kJ}$ $\mathrm{mol}^{-1}$.

Table 1 summarizes the energetical data obtained in the present study, including the calculated energy barriers for

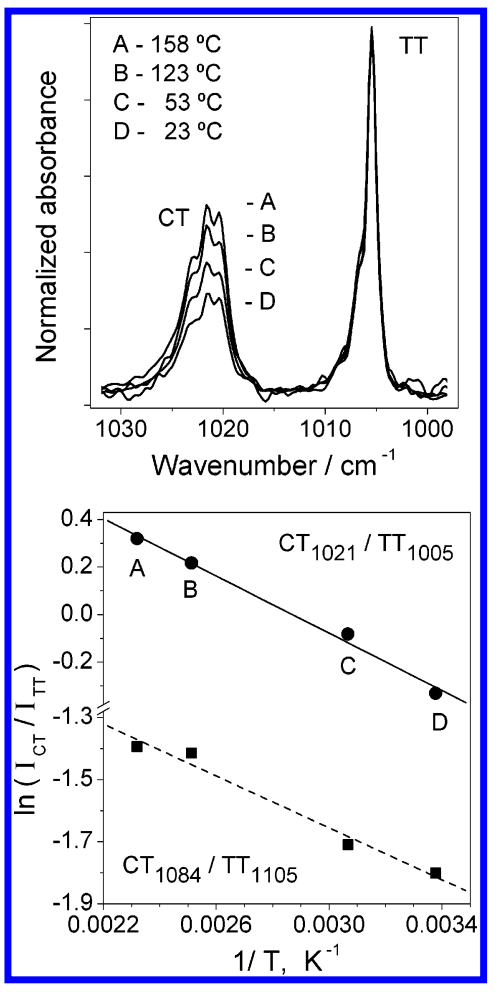

Figure 3. The upper frame shows two nonoverlapping infrared bands due to the TT and CT conformers of DCD isolated in argon matrixes at $10 \mathrm{~K}$. Traces A, B, C, and D present the fragments of FTIR spectra measured in different experiments. In each of the experiments the temperature of the vapor phase of the compound prior to deposition was different, as it is indicated in the figure. The experimental intensities are normalized to make the peak intensity due to the TT form equal for all temperatures. The lower frame shows Van't Hoff plots constructed using pairs of nonoverlapping experimental bands due the $\mathrm{CT}$ and TT conformers (band centers are indicated after conformer names as subscripts). Straight lines represent results of the least squares linear fits: solid line is for the $(1021,1005)$ pair (shown in the upper frame); dashed line is for the $(1084,1105)$ pair.

rotation of the methyl groups in the three conformers. This table also presents the calculated dipole moments of conformers TT, $\mathrm{CT}$, and $\mathrm{CC}$.

Vibrational Spectra. Comparison of the infrared spectrum of DCD isolated in solid argon with the spectra calculated for the conformers of the compound revealed that both conformers TT and CT were present in the as-deposited matrixes. Decreasing the temperature of the vapor prior to deposition led to an increase of the relative intensities of the bands ascribable to the conformer TT, with respect to those of conformer CT (see upper frame of Figure 2). The temperature dependence of the relative intensities of bands due to the two main conformers enabled an empirical distinction between the two sets of bands ascribable to forms TT and CC. Inspection of the whole experimental spectrum revealed that in the region 980-1120 $\mathrm{cm}^{-1}$ there are two bands of medium intensity due to conformer TT and two bands that originated in the form CT (Figure 2). These bands do not overlap and allow reliable determination of their intensities, which served as a measure of the conformational populations.

Carrying out a series of independent experiments, where the temperature of the equilibrium gas phase of the compound was varied between 23 and $158{ }^{\circ} \mathrm{C}$ (Figure 3), enabled a shift of the relative populations of the two experimentally relevant conformers present in the matrixes. This allowed direct experimental determination of the relative conformational enthalpies from the Van't Hoff plot shown in Figure $3 .^{1}$ A value of $-\Delta H^{\circ}=4.2$ 
TABLE 2: Vibrational Frequencies, Intensities, ${ }^{a}$ and Potential Energy Distributions $\left(\right.$ PED) for Conformer I of DCD $\left(C_{2 v}\right.$; TT Conformer) ${ }^{b}$

\begin{tabular}{|c|c|c|c|c|c|}
\hline \multicolumn{2}{|c|}{$\begin{array}{c}\text { obsd } \\
\text { infrared, Ar matrix } \\
T=10 \mathrm{~K}\end{array}$} & \multicolumn{2}{|c|}{$\begin{array}{c}\text { calcd } \\
\text { B3LYP/6-311++G(d, p) }\end{array}$} & \multirow[b]{2}{*}{ sym } & \multirow[b]{2}{*}{$\operatorname{PED}^{d}(\%)$} \\
\hline$v$ & $I$ & $v^{c}$ & $I$ & & \\
\hline 3035.8 & 10.3 & $\{3067.5$ & 12.8 & $\mathrm{~A}_{1}$ & $v\left(\mathrm{CH}_{3}\right)_{\text {as }}(97)$ \\
\hline 3035.8 & 10.3 & 3067.4 & 5.5 & $\mathrm{~B}_{2}$ & $v\left(\mathrm{CH}_{3}\right)_{\mathrm{as}}(97)$ \\
\hline 3018.7 & 12.7 & 3037.6 & 26.0 & $\mathrm{~B}_{1}$ & $v\left(\mathrm{CH}_{3}\right)_{\mathrm{as}}(100)$ \\
\hline 2987.1 & 12.1 & 3037.5 & 0 & $\mathrm{~A}_{2}$ & $\begin{array}{l}\nu\left(\mathrm{CH}_{3}\right)_{\text {as }}(100) \\
\text { combination }(1629.2+1361.3=2990.5)\end{array}$ \\
\hline 2965.8 & 58.9 & $\left\{\begin{array}{l}2960.7 \\
2960.4\end{array}\right.$ & $\begin{array}{r}0.7 \\
64.4\end{array}$ & $\begin{array}{l}\mathrm{A}_{1} \\
\mathrm{~B}_{2}\end{array}$ & $\begin{array}{l}v\left(\mathrm{CH}_{3}\right)_{s}(97) \\
v\left(\mathrm{CH}_{3}\right)_{\mathrm{s}}(97)\end{array}$ \\
\hline $\begin{array}{l}2870.4 \\
1860.1\end{array}$ & $\begin{array}{l}8.3 \\
2.9\end{array}$ & & & & $\begin{array}{l}\text { overtone }(2 \times 1474.4=2948.8) \\
\text { combination }[950.1+(924.1+913.5) / 2=1868.9]\end{array}$ \\
\hline $\begin{array}{l}1833.8 \\
1828.6\end{array}$ & & & & & \\
\hline $\left.\begin{array}{l}1826.1 \\
1813.8 \\
1811.9\end{array}\right\}$ & 95.6 & 1819.4 & 159.5 & $\mathrm{~A}_{1}$ & $v(\mathrm{C}=\mathrm{O})_{\mathrm{s}}(70)+v(\mathrm{C}-\mathrm{O})_{\mathrm{s}}(10)$ \\
\hline $\left.\begin{array}{l}1780.6 \\
1756.9 \\
1755.2\end{array}\right)$ & 52.5 & & & & combination $(827.8+950.1=1777.9)$ \\
\hline $\left.\begin{array}{l}1746.4 \\
1744.6 \\
1738.4\end{array}\right\}$ & 305.4 & 1765.7 & 378.5 & $\mathrm{~B}_{2}$ & $v(\mathrm{C}=\mathrm{O})_{\mathrm{as}}(87)+\delta \operatorname{ring}(10)$ \\
\hline 1682.5 & 24.3 & & & & combination $(1105.7+567.7=1673.4)$ \\
\hline 1655.4 & 18.8 & & & & overtone $(2 \times 827.8=1655.6)$ \\
\hline 1629.2 & 774.7 & 1625.5 & 662.9 & $\mathrm{~A}_{1}$ & $v(\mathrm{C} 3=\mathrm{C} 4)(40)+v(\mathrm{C}-\mathrm{O})_{\mathrm{s}}(29)+v(\mathrm{C}=\mathrm{O})_{\mathrm{s}}(17)$ \\
\hline $\left.\begin{array}{l}1475.4 \\
1474.4\end{array}\right\}$ & 301.0 & 1470.7 & 256.9 & $\mathrm{~B}_{2}$ & $\delta\left(\mathrm{CH}_{3}\right)_{\mathrm{s}}(68)+v(\mathrm{C}-\mathrm{O})_{\mathrm{as}}(18)$ \\
\hline 1457.9 & 17.3 & 1459.1 & 19.8 & $\mathrm{~A}_{1}$ & $\delta\left(\mathrm{CH}_{3}\right)_{\mathrm{as}}(88)+\gamma\left(\mathrm{CH}_{3}\right)_{\mathrm{as}}(10)$ \\
\hline 1454.3 & 34.6 & $\left\{\begin{array}{l}1457.1 \\
14570\end{array}\right.$ & 11.4 & $\mathrm{~B}_{2}$ & $\delta\left(\mathrm{CH}_{3}\right)_{\text {as }}(82)$ \\
\hline 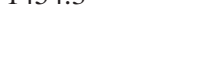 & (3. & $\begin{array}{l}1457.0 \\
1456.7\end{array}$ & $\begin{array}{c}24.2 \\
0\end{array}$ & $\begin{array}{l}\mathrm{B}_{1} \\
\mathrm{~A}_{2}\end{array}$ & $\begin{array}{l}\delta\left(\mathrm{CH}_{3}\right)_{\mathrm{as}}(92) \\
\delta\left(\mathrm{CH}_{3}\right)_{\mathrm{as}}(92)\end{array}$ \\
\hline 1435.3 & 95.6 & 1436.4 & 61.2 & $\mathrm{~A}_{1}$ & $\delta\left(\mathrm{CH}_{3}\right)_{\mathrm{s}}(96)$ \\
\hline $\left.\begin{array}{l}1367.1 \\
1361.3\end{array}\right\}$ & 790.7 & 1355.6 & 874.0 & $\mathrm{~B}_{2}$ & $v(\mathrm{C}-\mathrm{O})_{\mathrm{as}}(49)+\delta\left(\mathrm{CH}_{3}\right)_{\mathrm{s}}(25)+v(\mathrm{C}-\mathrm{C})_{\mathrm{as}}(11)$ \\
\hline 1262.6 & 13.4 & 1255.0 & 33.6 & $\mathrm{~A}_{1}$ & $\gamma\left(\mathrm{CH}_{3}\right)_{\mathrm{as}}(32)+v(\mathrm{C}-\mathrm{O})_{\mathrm{s}}(20)+v(\mathrm{C} 3=\mathrm{C} 4)(14)+v(\mathrm{C}-\mathrm{C})_{\mathrm{s}}(10)$ \\
\hline $\left.\begin{array}{l}1187.6 \\
1180.7\end{array}\right\}$ & 26.5 & 1183.9 & 21.4 & $\mathrm{~B}_{2}$ & $\gamma\left(\mathrm{CH}_{3}\right)_{\mathrm{as}}(80)$ \\
\hline 1152.9 & 0.8 & $\begin{array}{l}1146.5 \\
1146.1\end{array}$ & $\begin{array}{l}1.3 \\
0\end{array}$ & $\begin{array}{l}\mathrm{B}_{1} \\
\mathrm{~A}_{2}\end{array}$ & $\begin{array}{l}\gamma\left(\mathrm{CH}_{3}\right)_{\text {as }}(91) \\
\gamma\left(\mathrm{CH}_{3}\right)_{\text {as }}(91)\end{array}$ \\
\hline not obsd & & 1135.5 & 0.2 & $\mathrm{~A}_{1}$ & $\gamma\left(\mathrm{CH}_{3}\right)_{\mathrm{as}}(53)+v(\mathrm{C}-\mathrm{C})_{\mathrm{s}}(14)+v(\mathrm{C} 3=\mathrm{C} 4)(13)$ \\
\hline 1105.7 & 122.9 & 1101.7 & 96.9 & $\mathrm{~B}_{2}$ & $v(\mathrm{C}-\mathrm{C})_{\mathrm{as}}(29)+v(\mathrm{O}-\mathrm{Me})_{\mathrm{as}}(29)+\delta(\mathrm{C}-\mathrm{O})_{\mathrm{s}}(24)$ \\
\hline 1005.4 & 57.8 & 995.9 & 43.2 & $\mathrm{~A}_{1}$ & $v(\mathrm{O}-\mathrm{Me})_{\mathrm{s}}(50)+v(\mathrm{C}-\mathrm{C})_{\mathrm{s}}(24)+v(\mathrm{C} 1-\mathrm{C} 2)(14)+\delta(\mathrm{C}=\mathrm{O})_{\mathrm{as}}(10)$ \\
\hline $\begin{array}{l}950.1 \\
924.1\end{array}$ & 17.5 & 943.4 & 28.7 & $\mathrm{~A}_{1}$ & $v(\mathrm{O}-\mathrm{Me})_{\mathrm{s}}(34)+v(\mathrm{C} 1-\mathrm{C} 2)(31)+\delta(\mathrm{C}=\mathrm{O})_{\mathrm{as}}(17)$ \\
\hline $\left.\begin{array}{l}918.9 \\
916.1 \\
913.5\end{array}\right\}$ & 84.7 & 910.8 & 72.1 & $\mathrm{~B}_{2}$ & $v(\mathrm{O}-\mathrm{Me})_{\mathrm{as}}(60)+v(\mathrm{C}-\mathrm{C})_{\mathrm{as}}(18)$ \\
\hline 827.8 & 30.0 & $\begin{array}{l}830.4 \\
741.2\end{array}$ & $\begin{array}{c}19.6 \\
0\end{array}$ & $\begin{array}{l}\mathrm{B}_{2} \\
\mathrm{~A}_{2}\end{array}$ & $\begin{array}{l}\delta(\mathrm{C}=\mathrm{O})_{\mathrm{s}}(60)+\delta(\mathrm{C}-\mathrm{O})_{\mathrm{s}}(24) \\
\gamma(\mathrm{C}=\mathrm{O})_{\mathrm{as}}(81)+\gamma \operatorname{ring}(18)\end{array}$ \\
\hline 638.4 & 38.6 & 646.7 & 36.9 & $\mathrm{~A}_{1}$ & $v(\mathrm{C}-\mathrm{C})_{\mathrm{s}}(38)+v(\mathrm{C}-\mathrm{O})_{\mathrm{s}}(22)+v(\mathrm{C} 1-\mathrm{C} 2)(21)$ \\
\hline not obsd & & 599.5 & 0.8 & $\mathrm{~B}_{1}$ & $\gamma(\mathrm{C}=\mathrm{O})_{\mathrm{s}}(51)+\gamma(\mathrm{C}-\mathrm{O})_{\mathrm{s}}(48)$ \\
\hline not obsd & & 584.1 & 1.6 & $\mathrm{~B}_{2}$ & $\delta$ ring $(64)+v(\mathrm{C}-\mathrm{O})_{\mathrm{as}}(19)$ \\
\hline & & 578.6 & 0 & $\mathrm{~A}_{2}$ & $\gamma(\mathrm{C}-\mathrm{O})_{\mathrm{as}}(101)$ \\
\hline & & 410.2 & 0.9 & $\mathrm{~B}_{2}$ & $\delta(\mathrm{COMe})_{\mathrm{as}}(50)+v(\mathrm{C}-\mathrm{C})_{\mathrm{as}}(21)+\delta(\mathrm{C}=\mathrm{O})_{\mathrm{s}}(19)$ \\
\hline & & ( 357.0 & 6.2 & $\mathrm{~A}_{1}$ & $\delta(\mathrm{COMe})_{\mathrm{s}}(65)+v(\mathrm{C} 3=\mathrm{C} 4)(13)+\delta(\mathrm{C}-\mathrm{O})_{\mathrm{as}}(11)$ \\
\hline & & 301.6 & 3.0 & $\mathrm{~A}_{1}$ & $\delta(\mathrm{C}=\mathrm{O})_{\mathrm{as}}(68)+v(\mathrm{C} 1-\mathrm{C} 2)(24)$ \\
\hline & & 246.8 & 19.9 & $\mathrm{~B}_{1}$ & $\gamma(\mathrm{C}=\mathrm{O})_{\mathrm{s}}(47)+\gamma(\mathrm{C}-\mathrm{O})_{\mathrm{s}}(37)$ \\
\hline not investigated & & 205.4 & 7.5 & $\mathrm{~B}_{2}$ & $\delta(\mathrm{C}-\mathrm{O})_{\mathrm{s}}(43)+\delta(\mathrm{COMe})_{\mathrm{as}}(32)+v(\mathrm{C}-\mathrm{C})_{\mathrm{as}}(14)$ \\
\hline & & 167.8 & 0 & $\mathrm{~A}_{2}$ & $\tau(\mathrm{OMe})_{\mathrm{s}}(52)+\gamma \operatorname{ring}(25)+\tau\left(\mathrm{CH}_{3}\right)_{\mathrm{s}}(21)$ \\
\hline & & 164.3 & 6.9 & $\mathrm{~A}_{1}$ & $\delta(\mathrm{C}-\mathrm{O})_{\mathrm{as}}(74)+\delta(\mathrm{COMe})_{\mathrm{s}}(19)$ \\
\hline & & 122.2 & 3.8 & $\mathrm{~B}_{1}$ & $\tau(\mathrm{OMe})_{\mathrm{as}}(50)+\tau\left(\mathrm{CH}_{3}\right)_{\mathrm{as}}(30)+\gamma(\mathrm{C}-\mathrm{O})_{\mathrm{s}}(18)$ \\
\hline & & 105.1 & 0 & $\mathrm{~A}_{2}$ & $\gamma \operatorname{ring}(63)+\tau\left(\mathrm{CH}_{3}\right)_{\mathrm{s}}(16)+\tau(\mathrm{OMe})_{\mathrm{s}}(12)$ \\
\hline & & 51.0 & 2.6 & $\mathrm{~B}_{1}$ & $\tau\left(\mathrm{CH}_{3}\right)_{\mathrm{as}}(58)$ \\
\hline & & 43.6 & 0 & $\mathrm{~A}_{2}$ & $\tau\left(\mathrm{CH}_{3}\right)_{\mathrm{s}}(60)+\tau(\mathrm{OMe})_{\mathrm{s}}(36)$ \\
\hline
\end{tabular}

${ }^{a}$ Relative integrated intensities, normalized in such a way that the total measured intensity for each conformer is equal to the corresponding calculated intensity. ${ }^{b}$ Frequencies $(v)$ in $\mathrm{cm}^{-1}$; theoretical intensities $(I)$ in $\mathrm{km} \mathrm{mol}^{-1}$. ${ }^{c}$ Theoretical positions of absorption bands were scaled according to the equation: $y=26.8+0.96 x$. ${ }^{d}$ PED values lower than $10 \%$ are not included. Definition of symmetry coordinates is given in Table S01 (Supporting Information). See Scheme 1 for atom numbering. 
TABLE 3: Vibrational Frequencies, Intensities, ${ }^{a}$ and Potential Energy Distributions (PED) for Conformer II of DCD $\left(C_{s}\right.$; Conformer CT) ${ }^{b}$

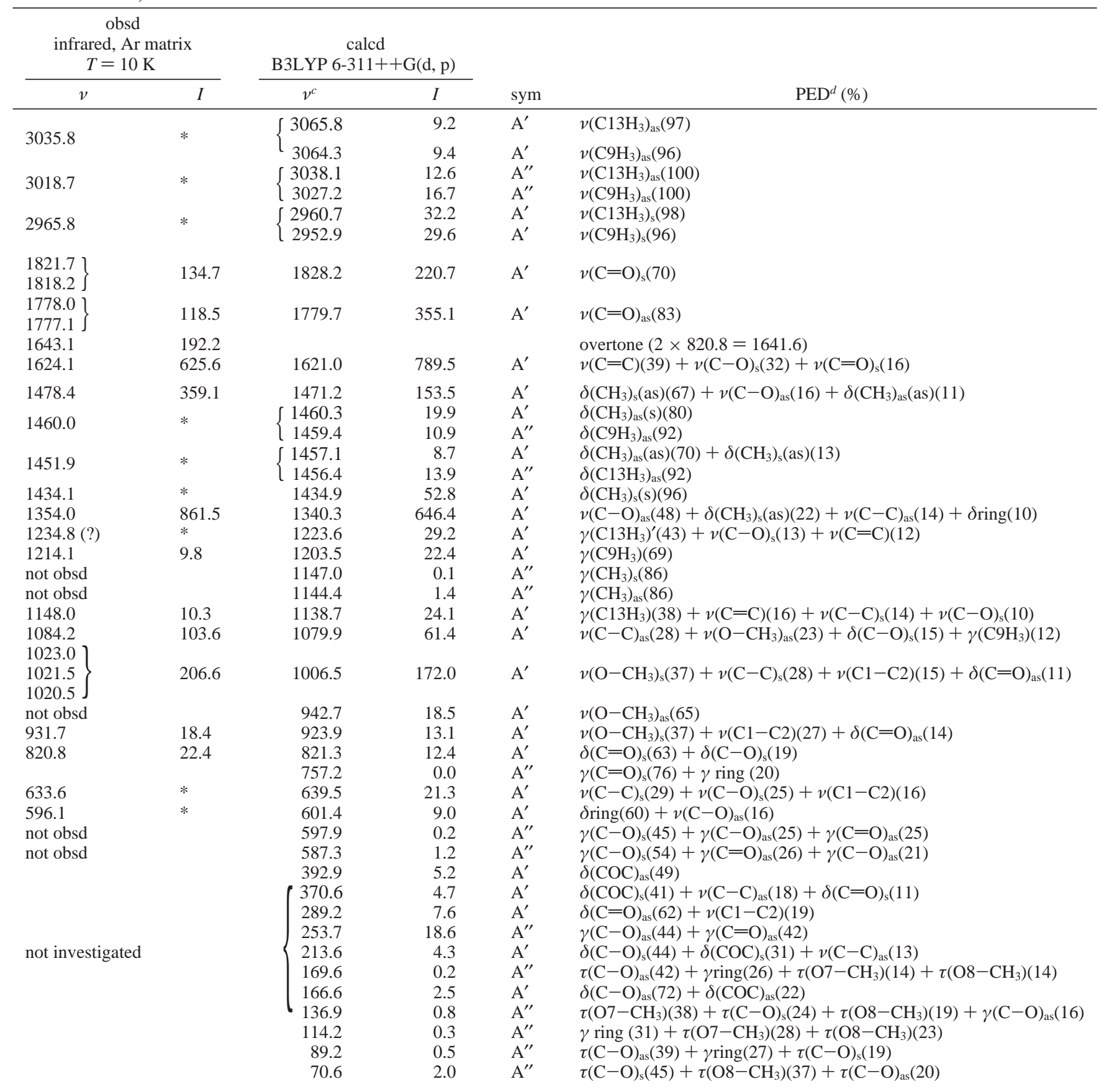

${ }^{a}$ Relative integrated intensities, normalized in such a way that the total measured intensity for each conformer is equal to the corresponding calculated intensity. The asterisk (*) designates an overlap with bands from the most stable isomer. ${ }^{b}$ Frequencies $(v)$ in $\mathrm{cm}^{-1}$; theoretical intensities (I) in $\mathrm{km} \mathrm{mol}^{-1}$ ]. ${ }^{c}$ Theoretical positions of absorption bands were scaled according to the equation: $y=26.8+0.96 \mathrm{x} .{ }^{d}$ PED values lower than $10 \%$ are not included. Definition of symmetry coordinates is given in Table S02 (Supporting Information). See Scheme 1 for atom numbering.

$\mathrm{kJ} \mathrm{mol}^{-1}$ was obtained (the experimental error in the enthalpy value is essentially dependent on the choice of the spectral baselines and estimated to be ca. 20\%.) and showed that form TT is (in the gaseous phase) more stable than conformer CT. In this estimation, it was assumed that no conformational interconversion occurs during matrix deposition at $10 \mathrm{~K}$, since the barrier separating the two experimentally relevant conformers is high (see Figure 1). The conclusion on preservation of the gas-phase populations during deposition of the matrixes is supported by the results of subsequent annealing of the argon matrixes up to ca. $35 \mathrm{~K}$. Such an annealing did not lead to any spectral changes that could be related with any conformational isomerization. Annealing of the matrixes to a higher temperature was precluded by loss of optical properties and significant evaporation of the matrixes.

The detailed assignment of the experimental spectra was facilitated by the excellent agreement between the experimental and theoretical data. In addition, as it will be described in detail in the next section, irradiation experiments also led to conformational isomerization, providing additional evidence supporting the band assignments presented in Tables 2 and 3. Besides experimental and theoretical frequencies and infrared intensities, these tables also present the results of the normal-coordinate analysis, with characterization of each normal vibration in terms of percent contributions from chosen symmetry coordinates (see also Tables S01 and S02, for definition of the coordinates). 


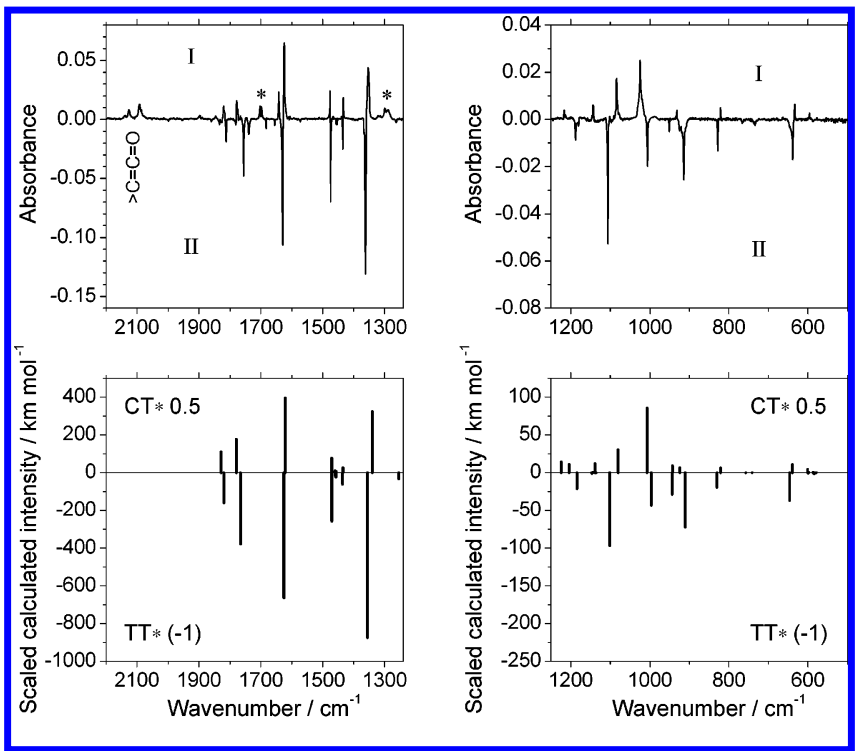

Figure 4. The upper frames show the $2200-1250 \mathrm{~cm}^{-1}$ and $1250-$ $550 \mathrm{~cm}^{-1}$ ranges of the difference experimental infrared spectra of DCD isolated in an argon matrix (the spectrum after 80 min of irradiation with $\lambda>337 \mathrm{~nm}$ cutoff filter minus the spectrum of the freshly deposited matrix). The growing bands are designated with "I" and the decreasing bands with "II". The bands marked with asterisks are due to 2,3-dimethoxycycloprop-2-ene-1-one (DCP) that is produced in trace amounts upon prolonged irradiation. This species is one of the main products generated from DCD upon irradiation with shorter-wavelength UV light (see text). The pair of absorptions designated as $(>\mathrm{C}=\mathrm{C}=$ $\mathrm{O})$ appear in the spectral region characteristic to bands due to stretching vibrations of the ketene group. Their origin is also discussed in the text. The lower frames show the same spectral ranges in the spectra of conformers TT and CT of DCD calculated at the DFT(B3LYP)/6$311++\mathrm{G}(\mathrm{d}, \mathrm{p})$ level of theory. All theoretical frequencies are scaled using the equation $v_{\text {scaled }}=26.8+0.96 v_{\text {calcd }}$. The theoretical intensities are scaled by $(-1)$ for TT and by 0.5 for CT. Note that in the spectra obtained from the vapor of the compound at $158{ }^{\circ} \mathrm{C}$ some very-lowintensity bands (e.g., at 1034 and $974 \mathrm{~cm}^{-1}$ ) resulting from thermal decomposition of DCD are observed. However, at this temperature, the amount of DCD undergoing thermal decomposition is still negligible. The study of the pyrolitic decomposition of DCD is not addressed in this work.

Irradiation of the Matrixes (Photochemistry Experiments). To investigate the photochemistry of matrix-isolated DCD, in situ irradiation of the matrixes was carried out using different wavelengths. Irradiation of the matrixes with a cutoff filter transmitting light $\lambda>375 \mathrm{~nm}$ did not result in any spectral changes.

Increasing the energy of the incident UV-light (irradiation with the $337 \mathrm{~nm}$ cutoff filter) resulted in spectral changes. Upon short irradiation time $(2 \mathrm{~min})$, all bands present in the initially deposited spectrum decreased, and a pair of new absorption bands situated around $2100 \mathrm{~cm}^{-1}$ emerged. Increasing irradiation time with the same wavelengths resulted in a slight continuous growth of this pair of bands. Additionally, prolonged irradiation led mostly to redistribution of the intensity of the bands present in the as-deposited matrix, with bands due to conformer TT continuously decreasing in intensity and bands due to conformer CT starting to increase after prolonged irradiation (Figure 4). No traces of conformer CC could be found in the spectra even after prolonged irradiation $(80 \mathrm{~min})$. This demonstrates that the high-energy form CC is either not produced, or it is converted quickly back to the most stable forms TT and CT. On the other hand, upon prolonged irradiation with this filter, small bands (that were not present in the spectrum of the as-deposited matrix) appeared in the $2160-2050 \mathrm{~cm}^{-1}, 1950-1850 \mathrm{~cm}^{-1}, 1750-$

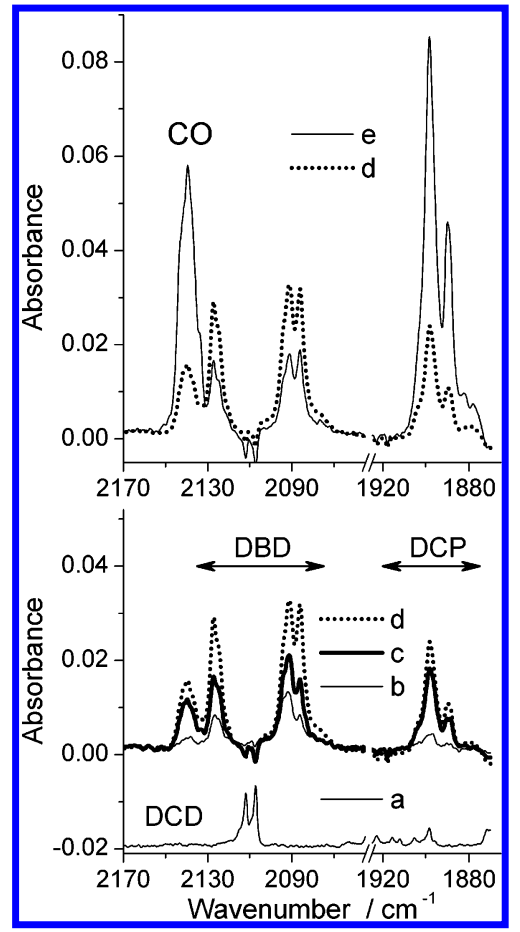

Figure 5. Observed infrared spectrum (2170-2050 and 1970-1870 $\mathrm{cm}^{-1}$ ranges) of DCD isolated in an argon matrix at $10 \mathrm{~K}$ (trace a) and difference spectra (traces $b-e$ ) (irradiated matrix minus as-deposited matrix) obtained after UV-irradiations of this sample with a xenon arc lamp and different cutoff filters: (lower frame, trace b) after $80 \mathrm{~min}$ irradiation with a cutoff filter $\lambda>337 \mathrm{~nm}$; (trace $\mathrm{c}$ ) after subsequent irradiation during $100 \mathrm{~min}$ with a cutoff filter $\lambda>285 \mathrm{~nm}$; (trace d) after additional irradiation during 2 min with a cutoff filter $\lambda>235$ $\mathrm{nm}$ (outer $\mathrm{KBr}$ window of the cryostat). Upper frame: (trace $\mathrm{d}$ ) the same as trace $d$ in the lower frame; (trace e) after 130 min irradiation through the outer $\mathrm{KBr}$ window of the cryostat (that works as a cutoff filter $\lambda>235 \mathrm{~nm}$ ).

$1650 \mathrm{~cm}^{-1}$, and $1350-1250 \mathrm{~cm}^{-1}$ spectral ranges. These bands are due to low amounts of products of photolysis of DCD (see the following detailed discussion).

After an irradiation (for $80 \mathrm{~min}$ ) with the $337 \mathrm{~nm}$ cutoff filter, the sample was submitted to an irradiation with the $285 \mathrm{~nm}$ cutoff filter (for $100 \mathrm{~min}$ ) and finally to a direct irradiation (for $130 \mathrm{~min})$ through the $\mathrm{KBr}$ outer window of the cryostat $(\lambda>$ $235 \mathrm{~nm}$ ). Along these steps of irradiation, bands due to different products of photolysis of DCD could be observed in the spectra. It could be expected that the trans - trans $\rightarrow$ cis - trans conformational conversion should also occur upon irradiation with shorter-wavelength UV light, but because of the simultaneous occurrence of the photolysis reactions it is impossible to probe this process.

Figure 5 presents selected spectra obtained during the photochemical study of matrix-isolated DCD. In the spectral regions shown in this figure, some of the most intense bands due to the photoproducts are observed. No IR absorptions due to fundamental vibrations of forms TT and TC of DCD are present in the spectral ranges shown in Figure 5 (trace a). In this spectrum, a doublet centered at ca. $2110 \mathrm{~cm}^{-1}$ is observed, which can be tentatively assigned to the combination tone associated with the intense bands observed at 1105.7 and 1005.4 $\mathrm{cm}^{-1}$, because of the fundamental $v(\mathrm{C}-\mathrm{C})$ and $v(\mathrm{O}-\mathrm{Me})$ vibrations in the most stable conformer TT of DCD. The origin of this doublet in conformer TT is unequivocal, since it exhibits a characteristic temperature behavior matching other TT absorptions. 
Other spectra presented in the figure correspond to difference spectra, where the spectrum of the as-deposited matrix (trace a) was subtracted from the spectra obtained after irradiation. Trace $b$ corresponds to the spectrum collected after $80 \mathrm{~min}$ of irradiation with the $337 \mathrm{~nm}$ cutoff filter. As mentioned above, during this irradiation the main observed spectral change corresponded to the $\mathrm{TT} \rightarrow \mathrm{CT}$ conformational conversion. Nevertheless, as it was also noticed above, a few additional bands were observed that are due to products of photolysis of DCD. The bands in the $2125 \mathrm{~cm}^{-1}$ region (main maxima at 2127.4, 2125.0, and $2123.5 \mathrm{~cm}^{-1}$ ) and in the range between 2100 and $2070 \mathrm{~cm}^{-1}$ (main maxima at 2094.2, 2092.3, 2091.1, 2086.2 , and $2083.5 \mathrm{~cm}^{-1}$ ) appear at nearly the same frequencies as the most intense bands theoretically predicted for the possible conformers of the bisketene, 2,3-dimethoxybuta-1,3-diene-1,4dione (DBD, see Figure S02), which can be produced from DCD by photocleavage of the $\mathrm{C}-\mathrm{C}$ intercarbonyl bond. $\mathrm{DBD}$ has six distinct conformers (shown in Figure S02; see also Table S08, where their relative energies, symmetries, dipole moments, and some relevant structural data are given). For all conformers, the stretching vibrations of the two ketene groups in DBD are predicted by the DFT calculations to give rise to very intense bands around 2135 and $2090 \mathrm{~cm}^{-1}$ (average absolute intensities equal to ca. 500 and $1240 \mathrm{~km} \mathrm{~mol}^{-1}$, respectively), thus nicely matching the frequencies of the observed bands. Very unfortunately, all the other bands originated in this compound are much less intense, and only two additional bands originated in this species could be experimentally observed (at ca. 1234 and $1060 \mathrm{~cm}^{-1}$ ). The complex structure of the bands at ca. 2125 $\mathrm{cm}^{-1}$ and $2100-2070 \mathrm{~cm}^{-1}$ as well as the different rate of growing along the irradiation time reflects the fact that several conformers of DBD are produced. However, the spectra of all conformers are theoretically predicted to be very similar (see Tables S09-S14), in particular in the regions where bands due to this compound could be identified, precluding any identification of individual conformers. The origin of the very small bands observed at $2138.4 \mathrm{~cm}^{-1}$ and in the $1950-1850 \mathrm{~cm}^{-1}$ region will be discussed later in the paper.

The spectrum corresponding to trace $\mathrm{c}$ in Figure 5 was obtained after irradiation of the matrix (for $100 \mathrm{~min}$ ) with the $285 \mathrm{~nm}$ cutoff filter (following the irradiation performed with the $337 \mathrm{~nm}$ cutoff filter). It is noticeable that when the filter transmitting light with $(\lambda>285 \mathrm{~nm})$ was used, the efficiency of the photolysis of DCD increased considerably, in comparison to the irradiation with the $337 \mathrm{~nm}$ cutoff filter. Irradiation through the $\mathrm{KBr}$ window of the cryostat $(\lambda>235 \mathrm{~nm})$ was found to promote such photolysis even more efficiently. Two spectra obtained under these experimental conditions are shown in Figure 5. Trace d corresponds to the spectrum that was obtained after 10 min of irradiation through the $\mathrm{KBr}$ window of the cryostat (following the previous steps of irradiation with the 337 and $285 \mathrm{~nm}$ cutoff filters). Trace e corresponds to the spectrum obtained after $130 \mathrm{~min}$ of irradiation through the $\mathrm{KBr}$ window of the cryostat (in a whole, the matrix was subjected to $310 \mathrm{~min}$ of irradiation). During the first stages of the last step of irradiation (through the $\mathrm{KBr}$ window of the cryostat), the intensities of the bands due to DBD increased considerably, whereas the intensities of the bands at $2138.4 \mathrm{~cm}^{-1}$ and in the $1950-1850 \mathrm{~cm}^{-1}$ region did not vary very much (Figure 5, lower frame). On the other hand, upon prolonged irradiation through the $\mathrm{KBr}$ window of the cryostat (ca. 25 min after starting this step of irradiation), the bands due to DBD started to decrease, while those observed at $2138.4 \mathrm{~cm}^{-1}$ and in the 1950$1850 \mathrm{~cm}^{-1}$ region increased considerably. After prolonged

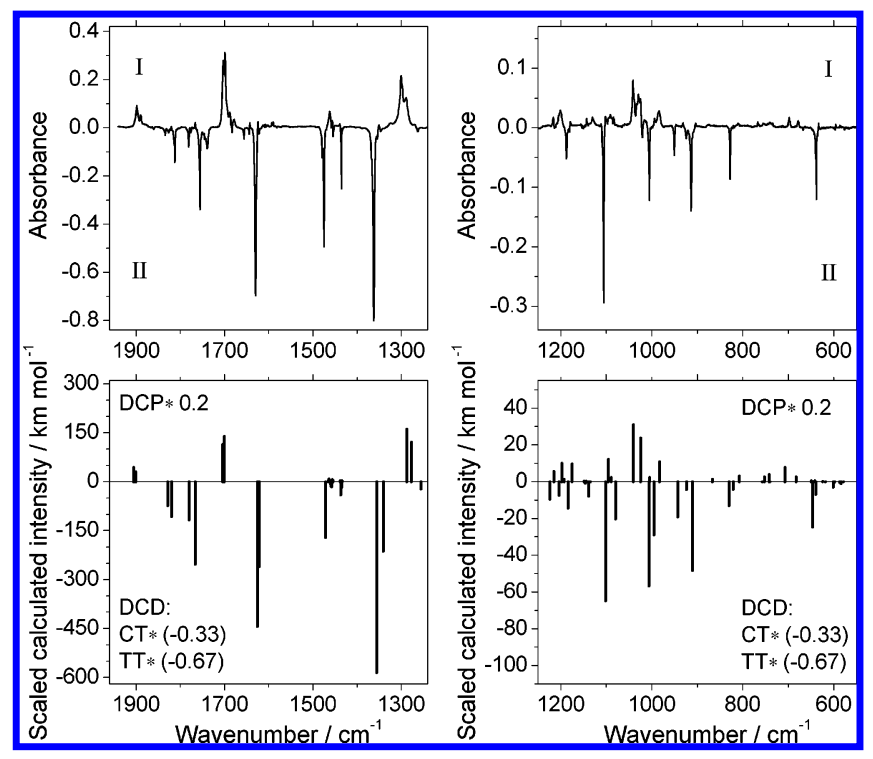

Figure 6. Upper frames show fragments of the experimental difference FTIR spectra of DCD isolated in an argon matrix (spectrum recorded before any irradiation minus spectrum at the end of the irradiation process). The growing bands are designated with "I" and the decreasing bands with "II". Lower frames show corresponding fragments of the theoretical spectra calculated at the DFT(B3LYP)/6-311++G(d,p) level. Bands pointing downward represent the superposition of the spectra calculated for the TT and CT conformers of DCD (the intensities of the calculated bands were scaled by the estimated ratio of TT and CC populations at $53^{\circ} \mathrm{C}$ ). Bands pointing upward represent the superposition of the spectra calculated for the trans-trans and cis-trans conformers of DCP (the intensities of the bands calculated for each of these conformers were scaled by 0.2). All theoretical frequencies were scaled using the equation $v_{\text {scaled }}=26.8+0.96 v_{\text {calcd }}$.

irradiation this trend became even more evident (Figure 5, upper frame). This means that the bisketene was produced at the first stages of the irradiation and then it was consumed in a secondary photoreaction, which yielded the products that give rise to the bands at $2138.4 \mathrm{~cm}^{-1}$ and in the $1950-1850 \mathrm{~cm}^{-1}$ region. The identification of the band at $2138.4 \mathrm{~cm}^{-1}$ is straightforward, since this is the characteristic band due to $\mathrm{CO}$ isolated in argon matrix. ${ }^{29,30}$ Indeed, the complex structure of the observed band shows that part of the photoproduced $\mathrm{CO}$ is associated with other species produced in the same matrix cage. The identification of the species giving rise to the bands appearing in the $1950-1850 \mathrm{~cm}^{-1}$ region could also be made easily. In fact, these IR absorptions belong to a set of bands, which show an uniform and characteristic pattern of variation of intensity with irradiation time. These bands are shown in Figure 6, and fit nicely the predicted spectra for the transtrans and cis-trans conformers of deltic acid dimethyl ester $\left(\mathrm{C}_{5} \mathrm{O}_{3} \mathrm{H}_{6} ; 2,3\right.$-dimethoxycyloprop-2-en-1-one; DCP). The two conformers of DCP are shown in Figure S03 (Supporting Information), whereas the band assignments are given in Tables 4 and 5, together with results of normal-coordinate analysis. DCP is produced together with $\mathrm{CO}$, and results from decarbonylation of the bisketene, probably involving intermediacy of the ketenylcarbene. ${ }^{23}$

The DFT(B3LYP)/6-311++G(d,p) calculations indicated that the trans - trans conformer of DCP should be more stable than the cis-trans form by $3.42 \mathrm{~kJ} \mathrm{~mol}^{-1}\left(3.59 \mathrm{~kJ} \mathrm{~mol}^{-1}\right.$, if zeropoint vibrational energy correction is considered). The spectroscopic data indicate that, at the end of the UV-irradiation, the two conformers are present in the matrix in a proportion that is equal to the degeneracy of the conformational level (1 for the trans - trans conformer and 2 for the cis - trans form). 
TABLE 4: Vibrational Frequencies, Intensities, ${ }^{a}$ and Potential Energy Distributions (PED) for Conformer I of DCP $\left(C_{2 v}\right.$; Conformer TT) ${ }^{b}$

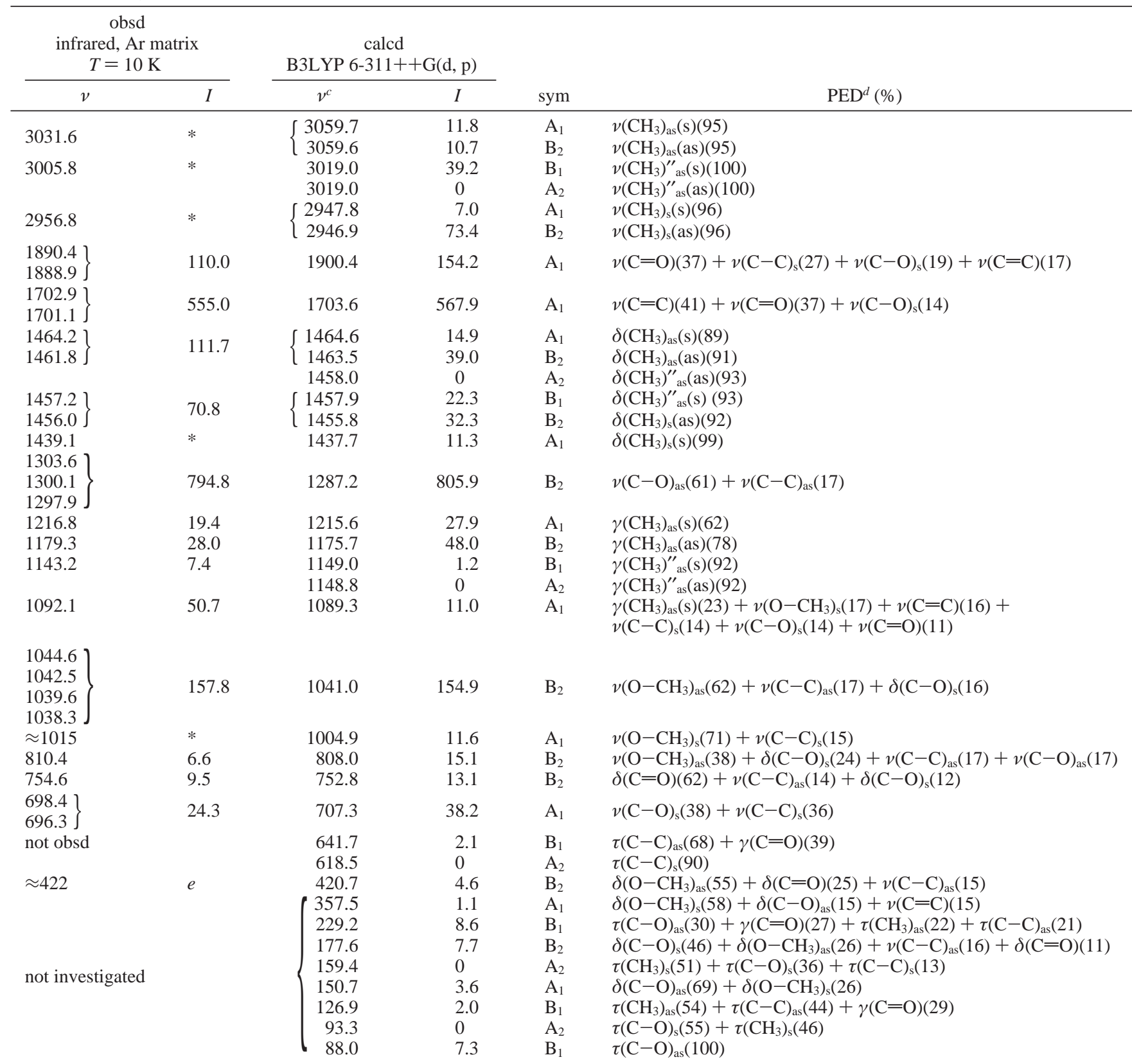

${ }^{a}$ Relative integrated intensities, normalized in such a way that the total measured intensity for each conformer is equal to the corresponding calculated intensity. The asterisk $(*)$ designates an overlap with bands from the most stable isomer. ${ }^{b}$ Frequencies $(v)$ in $\mathrm{cm}^{-1}$; theoretical intensities (I) in $\mathrm{km} \mathrm{mol}^{-1}$. ${ }^{c}$ Theoretical positions of absorption bands were scaled according to the equation $y=26.8+0.96 \mathrm{x}$. ${ }^{d}$ PED's lower than $10 \%$ are not included. Definition of symmetry coordinates is given in Table S05 (Supporting Information). See Figure S03 for atom numbering. ${ }^{e}$ Not possible to measure because of excessive spectral noise.

Indeed, the ratio of the integral intensities of the bands at 1890.4/ $1888.9 \mathrm{~cm}^{-1}$ (trans - trans) and $1898.4 \mathrm{~cm}^{-1}$ (cis-trans) matches almost perfectly that predicted theoretically ( 0.41 vs 0.35 ; see Tables 4 and 5).

The global kinetics of the photochemical processes is summarized in Figure 7. As shown in this figure, DBD is present at practically all stages of photoreaction, never exceeding $3 \%$ of the total population. This can be interpreted in terms of a photo equilibrium which is achieved fast. Also a small amount of this species confirms its role as an important reaction intermediate. The first UV $(\lambda>337 \mathrm{~nm})$ irradiation is nondestructive and results mainly in DCD TT $\rightarrow$ CT conformational isomerization. Upon UV $(\lambda>285 \mathrm{~nm})$ irradiation, this photoprocess progresses, but alongside with it a small amount of the decarbonylation product (DCP) is generated. When the matrix was exposed to $\mathrm{UV}(\lambda>235 \mathrm{~nm})$ light, production of DCP at the expense of DCD was the main observed photochemical transformation. The amount of photoproduced CT conformer of DCP is approximately twice greater than the amount of photogenerated TT conformer.

Having assigned the spectral signatures of the main photoproducts, it is now possible to discuss the mechanisms of the observed processes. One of the interesting issues concerns the initial stage of the phototransformations (partially depicted in Figure 4). On the basis of changes in the experimental spectra induced by low-energy UV $(\lambda>337 \mathrm{~nm})$ irradiation, two mechanisms of conformational isomerization in DCD can be proposed, either direct conversion or involving intermediacy of 
TABLE 5: Vibrational Frequencies, Intensities, ${ }^{a}$ and Potential Energy Distributions (PED) for Conformer II of DCP $\left(C_{s}\right.$; Conformer CT)

\begin{tabular}{|c|c|c|c|c|c|}
\hline \multicolumn{2}{|c|}{$\begin{array}{c}\text { obsd } \\
\text { infrared, Ar matrix } \\
T=10 \mathrm{~K}\end{array}$} & \multicolumn{2}{|c|}{$\begin{array}{c}\text { calcd } \\
\text { B3LYP 6-311++G(d, p) }\end{array}$} & \multirow[b]{2}{*}{ sym } & \multirow[b]{2}{*}{$\operatorname{PED}^{d}(\%)$} \\
\hline$v$ & $I$ & $v^{c}$ & $I$ & & \\
\hline \multirow{2}{*}{3031.6} & \multirow{2}{*}{ * } & $\{3058.4$ & 10.5 & $\mathrm{~A}^{\prime}$ & $v\left(\mathrm{C} 11 \mathrm{H}_{3}\right)_{\mathrm{as}}(95)$ \\
\hline & & $\{3058.0$ & 11.9 & $\mathrm{~A}^{\prime}$ & $v\left(\mathrm{C} 7 \mathrm{H}_{3}\right)_{\mathrm{as}}(94)$ \\
\hline 3005.8 & $*$ & 3019.5 & 19.0 & $A^{\prime \prime}$ & $v\left(\mathrm{C} 11 \mathrm{H}_{3}\right)^{\prime \prime}{ }_{\text {as }}(100)$ \\
\hline$\approx 3000$ & $*$ & 3012.0 & 22.3 & $\mathrm{~A}^{\prime \prime}$ & $v\left(\mathrm{C} \mathrm{H}_{3}\right)^{\prime \prime}{ }_{\text {as }}(100)$ \\
\hline \multirow{2}{*}{2956.8} & \multirow{2}{*}{$*$} & 2947.4 & 38.4 & $\mathrm{~A}^{\prime}$ & $v\left(\mathrm{C} 11 \mathrm{H}_{3}\right)_{\mathrm{s}}(96)$ \\
\hline & & 2941.7 & 35.0 & $\mathrm{~A}^{\prime}$ & $v\left(\mathrm{C} \mathrm{H}_{3}\right)_{\mathrm{s}}(94)$ \\
\hline 1898.4 & 266.2 & 1905.4 & 218.1 & $\mathrm{~A}^{\prime}$ & $v(\mathrm{C}=\mathrm{O})(42)+v(\mathrm{C}-\mathrm{C})_{\mathrm{s}}(28)+v(\mathrm{C}=\mathrm{C})(14)$ \\
\hline $\left.\begin{array}{l}1698.7 \\
1696.7\end{array}\right\}$ & 515.2 & 1700.0 & 692.8 & $\mathrm{~A}^{\prime}$ & $v(\mathrm{C}=\mathrm{C})(43)+v(\mathrm{C}=\mathrm{O})(33)+v(\mathrm{C} 2-\mathrm{O} 5)(10)$ \\
\hline 1465.3 & $*$ & 1464.8 & 19.8 & $\mathrm{~A}^{\prime}$ & $\delta\left(\mathrm{C} 11 \mathrm{H}_{3}\right)_{\mathrm{as}}(88)$ \\
\hline 1459.6 & $*$ & 1461.8 & 24.7 & $\mathrm{~A}^{\prime}$ & $\delta\left(\mathrm{C} \mathrm{H}_{3}\right)_{\mathrm{as}}(88)$ \\
\hline \multirow{2}{*}{1457.2} & \multirow[t]{2}{*}{$*$} & 1457.7 & 1.1 & $A^{\prime \prime}$ & $\delta\left(\mathrm{C} \mathrm{H}_{3}\right)^{\prime \prime}{ }_{\text {as }}(58)+\delta\left({\left.\mathrm{C} 11 \mathrm{H}_{3}\right)^{\prime \prime}{ }_{\text {as }}(35)}(35)\right.$ \\
\hline & & 1457.2 & 21.8 & $A^{\prime \prime}$ & $\delta\left(\mathrm{C} 11 \mathrm{H}_{3}\right)^{\prime \prime}{ }_{\mathrm{as}}(58)+\delta\left(\mathrm{C} \mathrm{H}_{3}\right)^{\prime \prime}{ }_{\text {as }}(35)$ \\
\hline 1456.1 & $*$ & 1454.2 & 21.2 & $\mathrm{~A}^{\prime}$ & $\delta\left(\mathrm{C} 11 \mathrm{H}_{3}\right)_{\mathrm{s}}(56)+\delta\left(\mathrm{C} \mathrm{H}_{3}\right)_{\mathrm{s}}(36)$ \\
\hline not obsd & & 1434.1 & 11.4 & $\mathrm{~A}^{\prime}$ & $\delta\left(\mathrm{C} \mathrm{H}_{3}\right)_{\mathrm{s}}(58)+\delta\left(\mathrm{C} 11 \mathrm{H}_{3}\right)_{\mathrm{s}}(40)$ \\
\hline 1288.7 & 605.9 & 1277.0 & 606.5 & $\mathrm{~A}^{\prime}$ & $v(\mathrm{C} 3-\mathrm{O} 6)(33)+v(\mathrm{C} 2-\mathrm{O} 5)(28)+v(\mathrm{C}-\mathrm{C})_{\mathrm{as}}(20)$ \\
\hline 1201.2 & \multirow[t]{2}{*}{98.2} & 1197.7 & 49.8 & $\mathrm{~A}^{\prime}$ & $\gamma\left(\mathrm{C} 11 \mathrm{H}_{3}\right)_{\mathrm{as}}(65)$ \\
\hline not obsd & & 1192.8 & 6.3 & $\mathrm{~A}^{\prime}$ & $\gamma\left(\mathrm{C} \mathrm{H}_{3}\right)_{\mathrm{as}}(79)$ \\
\hline \multirow{2}{*}{1143.2} & \multirow[t]{2}{*}{$*$} & $\{1148.5$ & 0.5 & $\mathrm{~A}^{\prime \prime}$ & $\gamma\left(\mathrm{C}_{\left.11 \mathrm{H}_{3}\right)^{\prime \prime}{ }_{\text {as }}(90)}\right.$ \\
\hline & & 1144.5 & 1.0 & $A^{\prime \prime}$ & $\gamma\left(\mathrm{C}_{7} \mathrm{H}_{3}\right)^{\prime \prime}{ }_{\text {as }}(90)$ \\
\hline 1092.1 & * & 1095.4 & 60.7 & $\mathrm{~A}^{\prime}$ & $\begin{array}{l}v(\mathrm{C}=\mathrm{C})(17)+\gamma\left(\mathrm{C} 11 \mathrm{H}_{3}\right)_{\mathrm{as}}(15)+ \\
\quad(\mathrm{C}-\mathrm{C})_{\mathrm{s}}(15)+v(\mathrm{C}=\mathrm{O})(12)+v(\mathrm{C} 3-\mathrm{O} 6)(11)\end{array}$ \\
\hline \multicolumn{2}{|l|}{1033.3} & \multirow[b]{2}{*}{1024.6} & \multirow[b]{2}{*}{118.5} & \multirow[b]{2}{*}{$\mathrm{A}^{\prime}$} & \multirow[b]{2}{*}{$v\left(\mathrm{O} 6-\mathrm{CH}_{3}\right)(58)+v(\mathrm{C}-\mathrm{C})_{\mathrm{as}}(14)+\delta(\mathrm{C} 3-\mathrm{O} 6)(11)$} \\
\hline $\left.\begin{array}{l}1032.5 \\
1029.7 \\
1024.5\end{array}\right\}$ & 172.6 & & & & \\
\hline $\left.\begin{array}{l}993.7 \\
984.2\end{array}\right\}$ & 73.5 & 983.2 & 54.3 & $\mathrm{~A}^{\prime}$ & $v\left(\mathrm{O} 5-\mathrm{CH}_{3}\right)(68)+v(\mathrm{C}-\mathrm{C})_{\mathrm{s}}(16)$ \\
\hline 874.8 & 15.4 & 867.2 & 6.1 & $\mathrm{~A}^{\prime}$ & $v(\mathrm{C} 2-\mathrm{O} 5)(17)+\delta(\mathrm{C} 2-\mathrm{O} 5)(17)+v\left(\mathrm{O} 6-\mathrm{CH}_{3}\right)(16)+v(\mathrm{C}-\mathrm{C})_{\mathrm{as}}(11)$ \\
\hline$\approx 740$ & 12.6 & 742.1 & 19.1 & $\mathrm{~A}^{\prime}$ & $\delta(\mathrm{C}=\mathrm{O})(59)+v(\mathrm{C}-\mathrm{C})_{\mathrm{as}}(13)$ \\
\hline 678.0 & 18.6 & 683.3 & 13.0 & $\mathrm{~A}^{\prime}$ & $v(\mathrm{C} 3-\mathrm{O} 6)(23)+v(\mathrm{C}-\mathrm{C})_{\mathrm{s}}(23)+v(\mathrm{C} 2-\mathrm{O} 5)(15)+\delta(\mathrm{C}=\mathrm{O})(10)$ \\
\hline not obsd & & 649.9 & 2.1 & $A^{\prime \prime}$ & $\tau(\mathrm{C}-\mathrm{C})_{\mathrm{as}}(69)+\gamma(\mathrm{C}=\mathrm{O})(32)$ \\
\hline not obsd & & 624.3 & 0.3 & $A^{\prime \prime}$ & $\tau(\mathrm{C}-\mathrm{C})_{s}(93)$ \\
\hline \multirow[t]{4}{*}{$\approx 422$} & \multirow[t]{4}{*}{$e$} & 426.3 & 8.2 & $\mathrm{~A}^{\prime}$ & $\delta\left(\mathrm{O} 6-\mathrm{CH}_{3}\right)(40)+\delta\left(\mathrm{O} 5-\mathrm{CH}_{3}\right)(23)+\delta(\mathrm{C} 3-\mathrm{O} 6)(12)$ \\
\hline & & 347.1 & 2.3 & $\mathrm{~A}^{\prime}$ & $\delta\left(\mathrm{O} 5-\mathrm{CH}_{3}\right)(33)+v(\mathrm{C}-\mathrm{C})_{\mathrm{as}}(21)+\delta(\mathrm{C}=\mathrm{O})(17)+\delta\left(\mathrm{O} 6-\mathrm{CH}_{3}\right)(17)$ \\
\hline & & 251.6 & 8.7 & $A^{\prime \prime}$ & $\gamma(\mathrm{C}=\mathrm{O})(48)+\tau(\mathrm{C}-\mathrm{C})_{\mathrm{as}}(38)+\tau\left(\mathrm{C} \mathrm{H}_{3}\right)(13)$ \\
\hline & & 191.5 & 2.0 & $\mathrm{~A}^{\prime}$ & $\begin{array}{l}\delta(\mathrm{C} 2-\mathrm{O} 5)(34)+\delta\left(\mathrm{O}^{2}-\mathrm{CH}_{3}\right)(16)+ \\
\quad(\mathrm{C} 3-\mathrm{O} 6)(14)+\delta\left(\mathrm{O} 5-\mathrm{CH}_{3}\right)(13)+v(\mathrm{C}-\mathrm{C})_{\mathrm{as}}(11)\end{array}$ \\
\hline \multirow{5}{*}{\multicolumn{2}{|c|}{ not investigated }} & 161.6 & 0.4 & $\mathrm{~A}^{\prime \prime}$ & $\tau\left(\mathrm{C} 11 \mathrm{H}_{3}\right)(36)+\tau(\mathrm{C} 3-\mathrm{O} 6)(32)+\tau\left(\mathrm{C} \mathrm{H}_{3}\right)(25)+\tau(\mathrm{C} 2-\mathrm{O} 5)(13)$ \\
\hline & & 141.7 & 4.0 & $\mathrm{~A}^{\prime}$ & $\delta(\mathrm{C} 3-\mathrm{O} 6)(42)+\delta(\mathrm{C} 2-\mathrm{O} 5)(26)+\delta\left(\mathrm{O} 5-\mathrm{CH}_{3}\right)(14)+\delta\left(\mathrm{O} 6-\mathrm{CH}_{3}\right)(11)$ \\
\hline & & 135.7 & 0.4 & $A^{\prime \prime}$ & $\tau\left(\mathrm{C} \mathrm{H}_{3}\right)(46)+\tau(\mathrm{C}-\mathrm{C})_{\mathrm{as}}(26)+\gamma(\mathrm{C}=\mathrm{O})(19)+\tau\left(\mathrm{C} 11 \mathrm{H}_{3}\right)(16)$ \\
\hline & & 108.6 & 0.3 & $\mathrm{~A}^{\prime \prime}$ & $\tau(\mathrm{C} 2-\mathrm{O} 5)(84)+\tau\left(\mathrm{C}_{7} \mathrm{H}_{3}\right)(13)+\tau(\mathrm{C} 3-\mathrm{O} 6)(11)$ \\
\hline & & 96.0 & 3.4 & $\mathrm{~A}^{\prime \prime}$ & $\tau(\mathrm{C} 3-\mathrm{O} 6)(66)+\tau\left(\mathrm{C} 11 \mathrm{H}_{3}\right)(30)+\tau(\mathrm{C} 2-\mathrm{O} 5)(10)$ \\
\hline
\end{tabular}

${ }^{a}$ Relative integrated intensities, normalized in such a way that the total measured intensity for each conformer is equal to the corresponding calculated intensity. The asterisk $(*)$ designates an overlap with bands from the most stable isomer. ${ }^{b}$ Frequencies $(v)$ in $\mathrm{cm}^{-1}$; theoretical intensities $(I)$ in $\mathrm{km} \mathrm{mol}^{-1}$ ]. ${ }^{c}$ Theoretical positions of absorption bands were scaled according to the equation $y=26.8+0.96 \mathrm{x} .{ }^{d}$ PED's lower than $10 \%$ are not included. Definition of symmetry coordinates is given in Table S06 (Supporting Information). See Figure S03 for atom numbering. ${ }^{e}$ Not possible to measure because of excessive spectral noise.

ring-opening and ring-closure processes. The direct TT $\rightarrow$ CT conversion in DCD implies the internal rotation around one of the $\mathrm{C}-\mathrm{O}$ bonds. This mechanism would require the quantitative phototransformation of the TT conformer into the CT form. However, as it is evident from Figure 4, the amount of consumed TT form exceeds approximately 2 times the amount of the photoproduced CT, which might be an indication of another mechanism. Nevertheless, this in not necessarily a proof for a mechanism other than the TT $\rightarrow$ CT direct conversion. It might be as well that the mechanism of $\mathrm{TT} \rightarrow \mathrm{CT}$ conversion is direct, but there occurs a simultaneous ring-opening side reaction.

According to the alternative mechanism, the first step of photoreaction would be the ring opening of DCD and formation of the bisketene intermediate (marked by $>\mathrm{C}=\mathrm{C}=\mathrm{O}$ in Figure 4). This is consistent with the observed direction of changes upon short irradiation times using the cutoff filter $\lambda>337 \mathrm{~nm}$ : the bands due to bisketene appear already at initial stages of the UV-induced phototransformations, while bands of both conformers of DCD decrease in intensity.

Another argument in favor of the second mechanism is that the amount of bisketene photoproduct is relatively low at all stages of the observed photoprocesses. This may indicate that bisketene (DBD) remains during irradiation in a dynamic reversible equilibrium with the starting compound (DCD), at the same time it is consumed in the DBD $\rightarrow$ DCP + CO process. Such behavior was observed recently by us for the case of a very branched photochemistry of sulfur analogues of $\alpha$-Pyrone, ${ }^{31}$ where the observed primary photoproducts of ring-opening reactions, ketene-thioaldehydes and thioketene-aldehydes, appeared fast upon short irradiations and were present in the matrixes in small amounts along all the process, being constantly consumed and produced. 


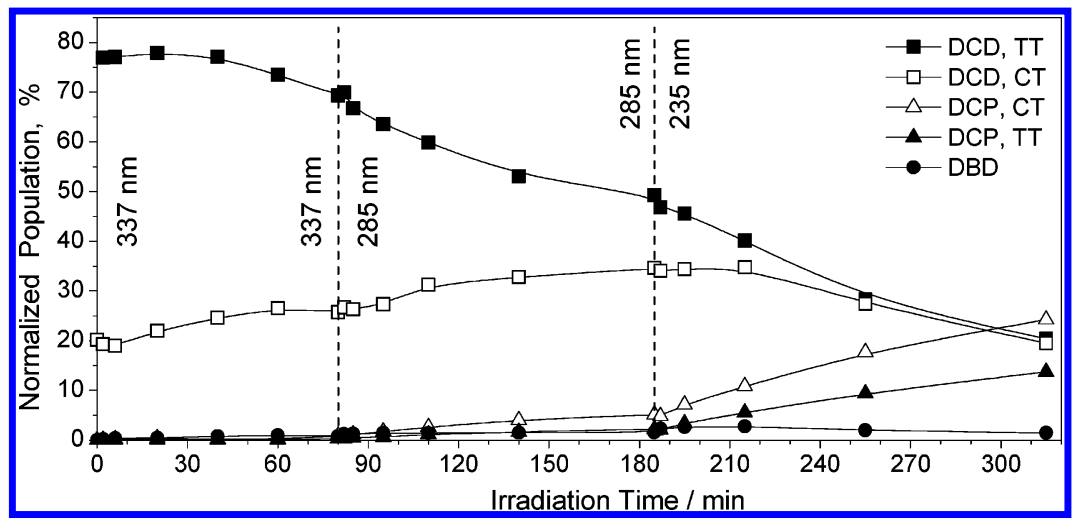

Figure 7. Kinetic evolution of selected species resulting from the consecutive UV irradiations (using different cutoff filters) of DCD isolated in an argon matrix. Changes of the cutoff filters $(337,285,235 \mathrm{~nm})$ are indicated by vertical dashed lines. Populations of the two conformers of the starting compound (DCD) are defined using pairs of the absorption bands at $1106,1005 \mathrm{~cm}^{-1}$ (TT, $\left.\mathbf{\square}\right)$ and $1084,1021 \mathrm{~cm}^{-1}$ (CT, $\square$ ). Integrated peak areas for these bands were reduced by the respective theoretical intensities calculated at the DFT(B3LYP)/6-311++G(d,p) level, averaged, and then normalized using a single scaling factor to $100 \%$ of the total. The same scaling factor was used for normalization of the amounts of photoproducts. The amounts of the two conformers of DCP (TT, $\Delta$ and CT, $\triangle$ ) were estimated by measuring integrated areas for the components of the doublet centered at 1890 and $1898 \mathrm{~cm}^{-1}$, respectively. The amount of DBD () was estimated using the pair of bands at 2127 and $2091 / 2086$ $\mathrm{cm}^{-1}$. The experimental integrated intensities were reduced using the averaged calculated intensities (for the two $\mathrm{C}=\mathrm{C}=\mathrm{O}$ stretching vibrations) over all possible (six) DBD conformers, averaged and normalized.

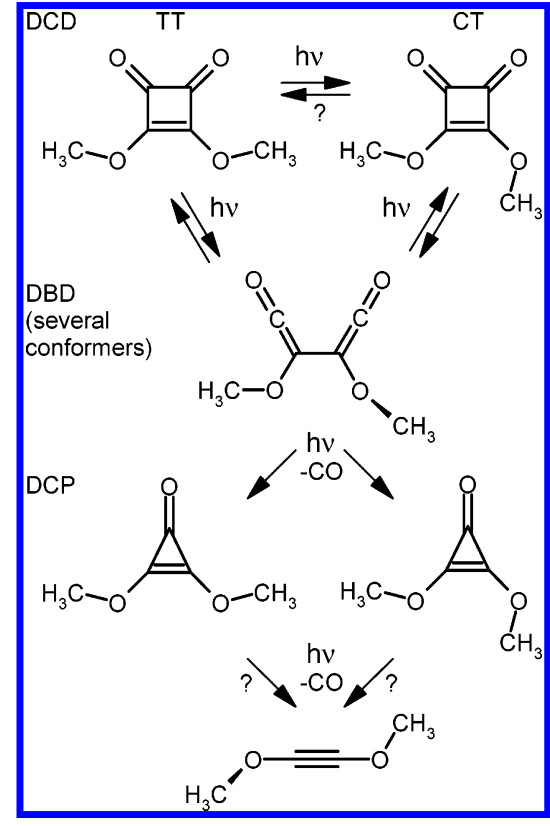

Figure 8. Overall scheme of the observed photo transformations. Note that there is some experimental indication of possible formation of dimethoxyacetylene, but the results presented in this study cannot be considered conclusive regarding this point (see text). These less evident results are indicated by question marks.

An additional point which might also favor this mechanism is that DBD is theoretically predicted to exist in six conformations, differing by the positions of methoxyl groups. This conformational multiplicity of DBD should result in conformational randomization of the species photochemically produced from DBD. This is exactly what was observed for both species which are related to the DBD photochemistry: DCD (the reactant species) and DCP (the methyl ester of deltic acid). The described mechanism is presented in Figure 8.

The final note should be done regarding the advanced stages of the photochemistry. It is also possible that DCP undergoes further reaction, with additional extrusion of $\mathrm{CO}$ and formation of dimethoxyacetylene (see also Figure S04 and Tables S07 and S15), though the experimental evidence of such process in the present study is not strong enough to be conclusive regarding this possibility. Nevertheless small bands at ca. 1324 and 946 $\mathrm{cm}^{-1}$, closely matching the strongest bands predicted theoretically for this molecule are observed in the spectrum recorded after prolonged irradiation of the matrix and are tentatively assigned to this species.

\section{Conclusions}

Two conformers, TT and CT, of dimethyl ester of squaric acid (DCD) were frozen from the gas phase into low-temperature Ar matrixes. The TT conformer is more stable than the CT form. As a consequence, the population of the TT conformer trapped in Ar matrixes was higher than that of the CT form. A series of samples deposited from different gas-phase temperatures allowed determination of the difference in conformational enthalpies between the CT and TT forms, being $4.2( \pm 20 \%) \mathrm{kJ}$ $\mathrm{mol}^{-1}$, which is in good consonance with the MP2 theoretically predicted value $\left(3.9 \mathrm{~kJ} \mathrm{~mol}^{-1}\right)$.

Upon irradiation of DCD monomers isolated in Ar matrixes with low-energy UV light $(\lambda>337 \mathrm{~nm})$, the TT $\rightarrow$ CT transformation occurred, with all probability involving an $n \pi^{*}$ excitation of the compound..$^{32}$ Under these irradiation conditions, other photoproducts (DBD and DCP) were also generated in small amounts, which might indicate that the open-ring bisketene DBD serves as an intermediate in the $\mathrm{TT} \rightarrow \mathrm{CT}$ conversion in DCD.

Upon irradiation with shorter-wavelength UV light $(\lambda>285$ $\mathrm{nm})$ or $(\lambda>235 \mathrm{~nm})$, presumably involving $\pi \pi^{*}$ excitation of the compound, ${ }^{32}$ the ring opening reaction, leading to bisketene (DBD) occurred more efficiently. Several conformers of DBD were photoproduced in this phototransformation.

Subsequently, DBD was photochemically converted into CO and deltic acid dimethyl ester (DCP). This compound was photoproduced in two forms, trans - trans and cis - trans, with the ratio of populations of these forms equal to $1: 2$. This can be rationalized by assuming equal probability of obtaining each of the forms and by taking into account the double degeneracyby-symmetry of the cis-trans conformer.

The general scheme summarizing the photoprocesses induced by UV irradiation of monomers of DCD isolated in lowtemperature Ar matrixes is presented in Figure 8. Some aspects of this scheme are analogous to the scheme of photoreactions previously observed for matrix-isolated 3,4-dichloro-3-cyclobutene-1,2-dione. ${ }^{32,33}$ For this latter compound, similarly to 
DCD investigated in the current work, the bisketene photoproduct was generated already upon longer-wavelength UV ( $\lambda$ $>335 \mathrm{~nm}$ ) irradiation. In both cases, the bisketene product was further phototransformed (by cleavage of $\mathrm{CO}$ molecule) to a substituted deltic acid.

Acknowledgment. S.B. and I.R. acknowledge support from the FCT, Grants SFRH/BD/16119/2004 and SFRH/BPD/1661/ 2000. The S.B., I.R., and R.F. contribution to this work was also run under the POCI/QUI/48937/2004 project, which is partially supported by FEDER.

Supporting Information Available: Figure S01 (solid-state thin film UV absorption spectrum of DCD); Figures S02-S04 (calculated molecular structures of DBD and DCP conformers and of dimethoxyacetylene); Tables S01-S07 (definition of internal coordinates used in the normal coordinates analyses for reactant and photoproducts); Table S08 (relative energies, dipole moments, relevant dihedral angles, and bond lengths for DBD conformers); Tables S09-S14 (calculated vibrational data for DBD conformers); Table S15 (calculated vibrational data for dimethoxyacetylene). This material is available free of charge via the Internet at http://pubs.acs.org.

\section{References and Notes}

(1) Kojimo, K.; Fukumi, H.; Tabata, K.; Kurata, H.; Yasuda, H.; PCT Int. Appl. WO 94, 1994, 20, 489.

(2) Naito, Y.; Yoshikawa, T.; Matsuyama, K.; Yagi, N.; Arai, M.; Nakamura, Y.; Kaneko, T.; Yoshida, N.; Kondo, M. Eur. J. Pharmacol. 1995, 294, 47.

(3) Chandrakumar, N. S.; Pitzele, B. S. U.S. Pat. US 5354746, 1994.

(4) Harada, T. Jpn. Kokai Tokkyo Koho JP 07219139, 1995.

(5) Fleisher, N. A. PCT Int. Appl. WO 9507555, 1995.

(6) Zhou, L.; Zhang, Y.; Wu, L.; Li, J. THEOCHEM 2000, 497, 137.

(7) Hutchings, M. G.; Ferguson, I.; Allen, S.; Zyss, J.; Ledoux, I. J. Chem. Res., Synop. 1998, 244.

(8) Dory, M.; André, J.-M.; Delhalle, J.; Morley, J. O. J. Chem. Soc., Faraday Trans. 1994, 90, 2319.

(9) Rostkowska, H.; Nowak, M. J.; Lapinski, L.; Smith, D.; Adamowicz, L.; Spectrochim. Acta A 1997, 53, 959.

(10) Semmingsen, D.; Tun, Z.; Nelmes, R. J.; McMullan, R. K.; Koetzle, T. F. Z. Kristallogr. 1995, 210, 934.
(11) Samuelsen, E. J.; Semmingsen, D. J. Phys. Solids 1977, 38, 1275. (12) Samuelsen, E. J.; Fjaer, E.; Semmingsen, D. J. Phys. C: Solid State Phys. 1979, 12, 2007.

(13) Semmingsen, D. Acta Chem. Scand. 1973, 27, 3961.

(14) Mallory, F. B.; Roberts, J. D. J. Am. Chem. Soc. 1961, 83, 393.

(15) Blomquist, A. T.; LaLancette, E. A. J. Am. Chem. Soc. 1961, 83, 1387.

(16) Kasai, M.; Oda, M.; Kitahara, Y. Chem. Lett. 1978, 217.

(17) Hochstrasser, R.; Wirz, J. Angew. Chem., Int. Ed. Engl. 1989, 28, 181.

(18) Diederich, F.; Rubin, Y.; Chapman, O. L.; Goroff, N. S. Helv. Chim. Acta 1994, 77, 1441.

(19) Miller, R. D.; Kirchmeyer, S. J. Org. Chem. 1993, 58, 90.

(20) Adam, W.; Patterson, W. S. J. Org. Chem. 1995, 60, 7769.

(21) Liu, R.; Tidwell, T. T. J. Chem. Soc., Perkin Trans. 2 1996, 2757.

(22) Maier, G.; Rohr, C. Liebigs Ann. 1996, 307.

(23) Allen, A. D.; Colomvakos, J. D.; Diederich, F.; Egle, I.; Hao, X.; Liu, R.; Lusztyk, J.; Ma, J.; McAllister, M. A.; Rubin, Y.; Sung, K.; Tidwell, T. T.; Wagner, B. D. J. Am. Chem. Soc. 1997, 119, 12125.

(24) Becke, A. D. Phys. Rev. A: At., Mol., Opt. Phys. 1988, 38, 3098.

(25) Lee, C. T.; Yang, W. T.; Parr, R. G. Phvs. Rev. B: Condens. Matter Mater. Phys. 1988, 37, 785.

(26) Møller, Ch.; Plesset, M. S. Phvs. Rev. 1934, 46, 618.

(27) Schachtschneider, J. H., Technical Report; Shell Development Co.: Emeryville, CA, 1969.

(28) Frisch, M. J.; Trucks, G. W.; Schlegel, H. B.; Scuseria, G. E.; Robb, M. A.; Cheeseman, J. R.; Zakrzewski, V. G.; Montgomery, J. A., Jr.; Stratmann, R. E.; Burant, J. C.; Dapprich, S.; Millam, J. M.; Daniels, A. D.; Kudin, K. N.; Strain, M. C.; Farkas, O.; Tomasi, J.; Barone, V.; Cossi, M.; Cammi, R.; Mennucci, B.; Pomelli, C.; Adamo, C.; Clifford, S.; Ochterski, J.; Petersson, G. A.; Ayala, P. Y.; Cui, Q.; Morokuma, K.; Malick, D. K.; Rabuck, A. D.; Raghavachari, K.; Foresman, J. B.; Cioslowski, J.; Ortiz, J. V.; Stefanov, B. B.; Liu, G.; Liashenko, A.; Piskorz, P.; Komaromi, I.; Gomperts, R.; Martin, R. L.; Fox, D. J.; Keith, T.; Al-Laham, M. A. Peng, C. Y.; Nanayakkara, A.; Gonzalez, C.; Challacombe, M.; Gill, P. M. W.; Johnson, B. G.; Chen, W.; Wong, M. W.; Andres, J. L.; Head-Gordon, M.; Replogle, E. S.; Pople, J. A. Gaussian 98, revision A.9; Gaussian, Inc.: Pittsburgh, PA, 1998.

(29) Duvernay, F.; Chiavassa, T.; Borget, F.; Aycard, J. P. Chem. Phys 2004, 298, 241.

(30) Dubost, H.; Marguin, L. A. Chem. Phys. Lett. 1972, 17, 269

(31) Breda, S.; Reva, I.; Lapinski, L.; Cristiano, M. L. S.; Frija, L.; Fausto, R. J. Phys. Chem. A 2006, 110, 6415.

(32) Dogaru, D.; Pietri, N.; Aycard, J. P.; Hillebrand, M. J. Phys. Org. Chem. 2004, 17, 409.

(33) Mincu, I.; Hillebrand, M.; Allouche, A.; Cossu, M.; Verlaque, P.; Aycard, J. P.; Pourcin, J. J. Phys. Chem. 1996, 100, 16045. 